\title{
A New PMU-Based Fault Location Algorithm for Series Compensated Lines
}

\author{
Chi-Shan Yu, Chih-Wen Liu, Member, IEEE, Sun-Li Yu, and Joe-Air Jiang
}

\begin{abstract}
This paper presents a new fault location algorithm based on phasor measurement units (PMUs) for series compensated lines. Traditionally, the voltage drop of series device is computed by the device model in the fault locator of series compensated lines, but using this approach errors are induced by the inaccuracy of the series device model or the uncertainty operation mode of the series device. The proposed algorithm does not utilize the series device model and knowledge of the operation mode of the series device to compute the voltage drop during the fault period. Instead, the proposed algorithm uses two-step algorithm, prelocation step and correction step, to calculate the voltage drop and fault location. The proposed technique can be easily applied to any series FACTS compensated line. EMTP generated data using a $30-\mathrm{km}$ 34-kV transmission line has been used to test the accuracy of the proposed algorithm. The tested cases include various fault types, fault locations, fault resistances, fault inception angles, etc. The study also considers the effect of various operation modes of the compensated device during the fault period. Simulation results indicate that the proposed algorithm can achieve up to $99.95 \%$ accuracy for most tested cases.
\end{abstract}

Index Terms-FACTS, series compensation, synchronized phasor measurement units.

\section{INTRODUCTION}

$\mathbf{I}$ N THE last two decades, the power electronic applications to ac power systems have provided many benefits. Applying series compensation in power systems can increase power transfer capability, improve transient stability and damp power oscillations. However, since the variation of series compensation voltage remains uncertain during the fault period, the protection of power systems with series compensated lines is considered as one of the most difficult tasks and is an important subject of investigation for relay manufacturers and utility engineers.

Series compensated systems can be mainly catalogued into switched capacitors (SCs) systems and thyristor controlled switched capacitors (TCSCs) systems. Typically, the main problem in designing series capacitors protection systems is overvoltage protection of the capacitor itself. The new metal oxide varistor (MOV) has been widely used in recent years as an overvoltage protection device for the series capacitors. However, the nonlinear characteristic of MOV will affect the compensated voltage of $\mathrm{SCs} / \mathrm{MOV}$ in fault period. Moreover, additional transients introduced by the MOV systems will

Manuscript received February 1, 2000; revised June 13, 2001

C.-S. Yu and C.-W. Liu are with Department of Electrical Engineering, National Taiwan University, Taipei, Taiwan.

S.-L. Yu is with Department of Electrical Engineering, National Taiwan of Science and Technology, Taipei, Taiwan.

J.-A. Jiang is with Department of Electrical Engineering, Private Kuang-Wu Institute of Technology and Commerce, Taipei, Taiwan.

Publisher Item Identifier S 0885-8977(02)00588-5. also render the compensation voltage difficult to estimate. To resolve the problems mentioned above, [1] has proposed a piecewise approximation model of MOV for distance relay application. Although the equivalent impedance can be used to calculate compensation voltage, the piecewise approximation model of SCs/MOV is incorrect during the transient period after the fault inception or when the nonlinear resistor is in some conducting mode [5]. Additionally, the nonlinear thyristor controlled reactance (TCR) branch of the TCSCs [2], [3] systems will introduce some new difficulties in computing the compensation voltage. For example, when the fault current is large, the TCR branch will operate between the block mode and bypass mode [2]-[4] to protect the capacitor and MOV. On the other hand, when the fault current is small for the high impedance ground fault, the MOV does not conduct and the TCR branch will remain in the vernier mode operation. This will also introduce some oscillation into the compensation voltage. Such an oscillation of the series capacitor voltage will cause further oscillation in the fault current. For the above phenomena, an accurate simulation analysis for the fault location of series compensated lines is difficult to achieve. Implementing the fault location algorithm based on a model of series compensation devices thus becomes impractical.

Recently, some studies associated with the easy analysis of series device models have been proposed in [6]-[8] and all produce satisfactory results. However, these algorithms must still need to consider the model of series device to compute voltage drop, limiting the accuracy of fault location. For example, the protection functions of series devices are too simplified in [6], [7], while [8] ignores the switching among different operation modes that initiates from the protection function. Thus, those algorithms inevitably suffer errors due to inaccuracy of the adopted models. Since the algorithm proposed here need not utilize the series devices model, the uncertainties mentioned above can be resolved completely.

To overcome the above problems, various protective schemes utilizing information from traveling waves launched by disturbances have been suggested. The high frequency components in fault waveform present undesirable effects for most fault location algorithms and are essential for accurate fault detection and location [9], [10]. Meanwhile, a fault detection/location algorithm derived from traveling wave principles can cope with high frequency transients since these basically depend on the traveling wave phenomenon. Fault location methods based on traveling waves are independent of network configurations and installations. Thus, the method is suitable for the series compensated transmission line [11]. However, identifying the desired high frequency signal becomes problematic. Additionally, 
the need for a high sampling rate for identifying the signal also limits the application of the method.

The synchronized PMUs-based fault detector/locator technique has been proven effective for fault relaying of transmission line without series compensation device [12]-[14]. However, when the series compensation device is installed in the transmission line, the previous proposed technique must be incorporated with the series device model to estimate voltage drop of series device in fault location computation. This study proposes a new approach, only considering synchronous measurement data from both ends of the transmission line, to estimate fault location of a series-compensated transmission line. The proposed algorithm excludes voltage drop calculation of the series compensation device. Instead, two-iteration step, prelocation and correction steps are used to calculate voltage drop and estimate fault location. This simplifies precise fault location estimation. Besides, since this algorithm does not use the series device mode, the proposed fault locator is easier to design and implementation.

When the series compensation device is installed in the middle of transmission line buses where PMU is located, fault location must be decided with respect to the series compensation device. In [7], a simple selecting algorithm based on fault resistance has been proposed. This selecting algorithm is one-terminal based method and is not suitable for some fault cases. The investigation follows [7] in developing a skillful selecting algorithm based on two-terminal measurement. Section III and the Appendix will clearly demonstrate that the proposed selecting algorithm is superior to that in [7] in several ways. Not only can the proposed algorithm determine the correct faulted sides, it can also effectively double-check the fault types and achieve more physical insights of theory utilized.

To resolve the difficulties in determining the model of series compensation device under fault occurrence, this study presents a novel PMUs-based fault location scheme. The rest of this paper is organized as follows. Section II presents the system configuration of the proposed PMU based fault location technique and then lists the contributions made by this investigation. Next, Section III begins by describing the theory utilized to determine the fault location of a TCSC-compensated, short single-phase transmission line, whose capacitance charging effect is ignored. The proposed fault location technique is then extended into a two-step fault location algorithm for cases involving transmission line shunt capacitors. Furthermore, this section proposes a skillful selector for selecting the correct faulted sides with respect to series compensation device and proposes a method of double-checking the input fault types. A $345 \mathrm{kV}$ sample system is used to evaluate the accuracy of the proposed algorithms with respect to different fault types, fault locations, and fault resistance. Next, Section IV presents the simulation results of the performance evaluations. These simulation results come from extensive EMTP [19] tested case. Meanwhile, Section V discusses some special phenomena from the simulation studies in detail. Conclusions are finally made in Section VI.

\section{SYSTEM CONFIGURATION}

Fig. 1 illustrates the overall diagram of the PMU-based fault location system for a series compensated line. The phasor mea- surement units are installed at both ends of the transmission line. The three phase voltages and three phase currents are measured simultaneously by PMUs at both ends of line. The global synchronism clock generator (GSCG) [13] has been built in the PMUs to provide an extremely accurate and reliable external reference clock signal. The sampling synchronization of PMU-GSCG configuration has been verified via field tests of Taipower $161 \mathrm{kV}$ substations to an accuracy of better than 1 ms. The performance of the proposed PMU units has also been proved in [13], [14].

The proposed algorithms are tested using the data generated from EMTP. The EMTP simulated voltage and current waveforms were taken directly as the synchronized sampled data (voltages and currents) from substations. The simulation example is a $300-\mathrm{km} 345-\mathrm{kV}$ transmission line. This work uses a new discrete Fourier transform based algorithm [smart discrete Fourier transform (SDFT)] to calculate the fundamental phasors. For more details, readers should consult [13], [15], [16]. These phasors are then transformed by Sequence transformation [17] and used as the input data of the new fault location algorithm. Next, the proposed locator performs subroutines 1 and 2 for simultaneously computing the fault locations $\left(\mathbf{D}_{L}, \mathbf{D}_{R}\right)$ and equivalent impedance of the series device $\left(\mathbf{Z}_{S E L}, \mathbf{Z}_{S E R}\right)$. This step uses the Gauss-Seidel numerical method [18]. During this stage, the technique generates two fault locations respectively belonging to either side of the series device, however, only one is precise. In succeeding step, the proposed selector can select the correct fault location. Finally, the proposed model uses the output (D, $Z_{S E}$ ) of the selector to double check the fault type. This procedure determines whether or not the input fault type is correct or not. It should be noted that, due to limited space, the issues of fault detector associated with the series-compensated line are ignored here and will be dealt with in a later investigation.

The main contributions of this work are as follows.

1) A novel fault location algorithm based on synchronized measurements is developed, in which the series device model is not required.

2) The proposed location algorithm is suitable for any series compensated FACTS devices that have no additional shunt branch or phase shift contribution on line currents.

3) Simulation results demonstrate that the proposed algorithm is effective in choosing correct fault location with respect to the series device.

4) A method is successfully proposed for double-checking the input fault types.

5) This work successfully applies the proposed algorithm to EMTP based systems, in which an accuracy of up to 99.95\% is achieved for most tested cases.

\section{PRINCIPLES}

The proposed algorithm is derived using the following assumptions:

1) the fault impedance is pure resistance;

2) the fault type is known.

The assumptions above are common in the literature dealing with the fault location issue. 


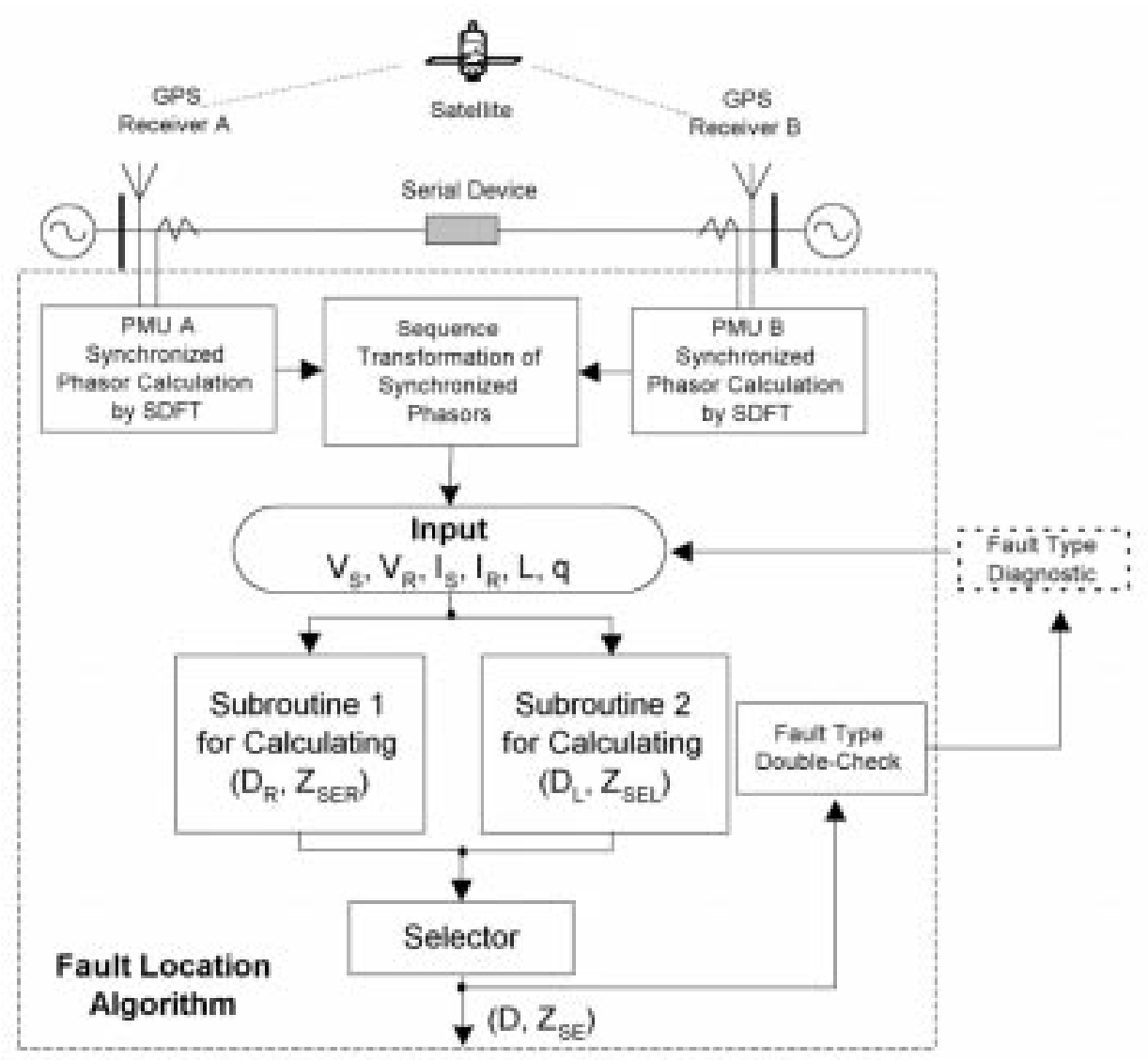

Fig. 1. System configuration.

The basic principle of the proposed algorithm is first illustrated via a simple single-phase case and is then extended to the case of a three-phase transmission line with shunt capacitance.

\section{A. TCSC and Its Operation Mode}

This work only considers the thyristor controlled series compensator (TCSC), and ignores other series compensation devices. However, the fault location technique proposed here can be easily extended to any type of series compensation device that has no additional shunt branch or phase shift contribution on line current. Fig. 2 shows the basic structure of TCSC. During the fault period, this study considers three different operation modes that are controlled by the protection function of TCSC [4]. The basic principles of these modes and the switching policy between them are briefly described as follows.

1) Vernier Mode: In high-impedance fault cases, TCSC constantly remains in its vernier mode of normal operation. Therefore, the protection function of the TCSC device does not work. The TCR branch is triggered by its prespecified firing angle. The TCSC works as a variable impedance. Voltage or current signals may exhibit subsynchronous resonance oscillation in this mode.

2) Block Mode: When the TCSC detects the overvoltage, the TCR branch stop its firing sequence by a protection function. Herein, the TCSC device works as a series capacitor parallel combination with a MOV. In considering the equivalent MOV circuit proposed in [1], the combination characteristic

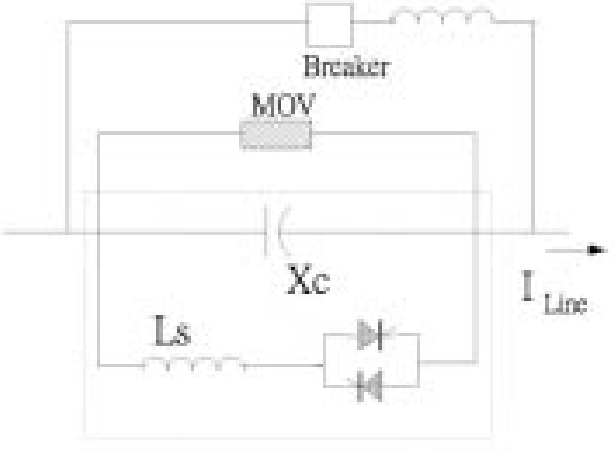

Fig. 2. Basic structure of TCSC.

can be considered a resistance series combination with a capacitor. Since the high resistance characteristic is introduced by the MOV, the subsynchronous resonance will decrease in voltage and current signals and the exponential dc-offset [15] activity in this mode.

3) Bypass Mode: When the energy absorbed in the MOV exceeds its limitation, the TCR branch enters its bypass mode to protect the MOV and capacitor, and the TCSC from the Block mode entering their bypass modes. In this mode, the TCR branch conducts in the whole cycle, and the TCSC device serves as a small value inductance. The voltage and current signals will only contain a exponential dc-offset since the TCSC equivalent impedance is pure inductance. 


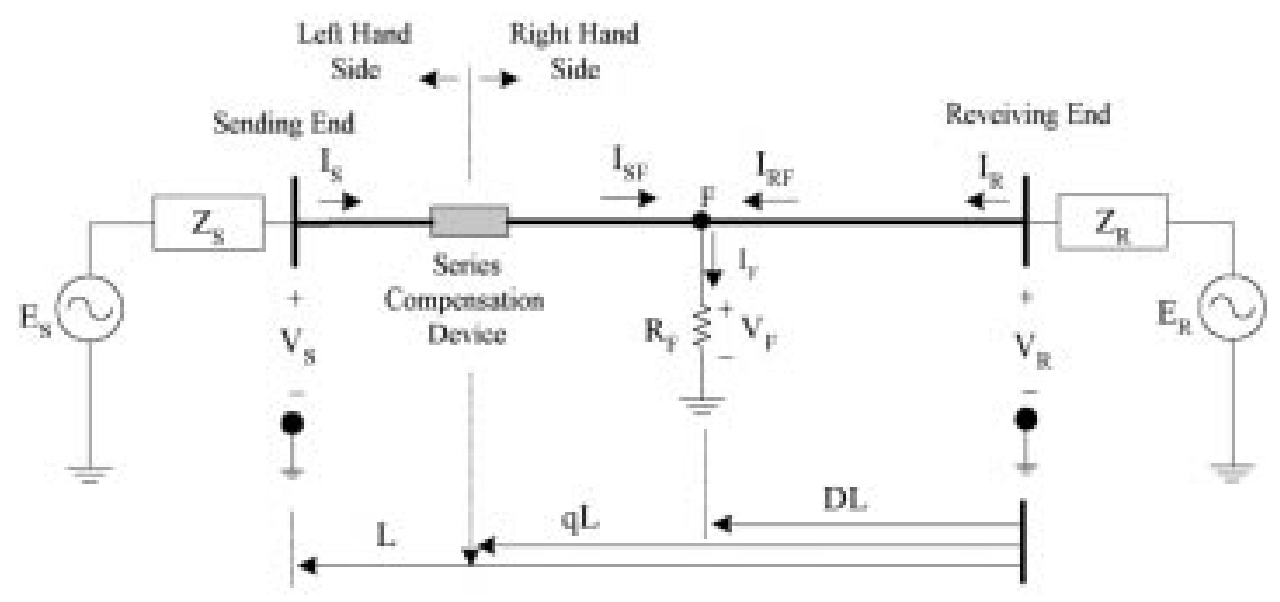

Fig. 3. Ground faulted transmission line.

This study considers all of the above three modes to demonstrate the protection of TCSC in detail.

\section{B. Single Phase • Illustrative Case}

To illustrate the basic idea of the proposed algorithms, this work first considers the single-phase series compensated line represented in Fig. 3. It considers the line as a short distance transmission line, that is, it ignores the shunt capacitance of the line. The series compensation device is installed at a distance of $q$ [p.u.] away from the receiving end of the considered line.

First, the fault is assumed to be located on the right side of the series compensation device. According to Fig. 3, the midway fault occurs at point $F$ which is $x=\mathrm{D}_{R} L(\mathrm{~km})$ away from the receiving end $R$ of transmission line $S R$. The total length of the transmission line is $L$ kilometers, and $\mathbf{D}_{R}$ (p.u.) is the per unit distance from receiving end to fault location. When a fault occurs at point $F$, the transmission line is divided in two line sections. One is line section $S F$, while the other is line section $R F$.

Using the assumption 1, it is easy to obtain that the phase relationship at point $F$ can be expressed as

$$
\operatorname{Arg}\left(\mathbf{V}_{F}\right)=\operatorname{Arg}\left(\mathbf{I}_{F}\right)
$$

where the $\operatorname{Arg}(\bullet)$ represents the phase angle.

Since the ground fault occurs on the right-hand side of the series compensation device, the line section $R F$ can still be regarded as a perfect transmission line (no series device). Thus, the voltage at any point on the line section $R F$ (including the fault end point) can be easily solved by $K V L$, i.e.,

$$
\mathbf{V}_{F}=\mathbf{V}_{R}-\mathbf{I}_{R} \mathbf{D}_{R} \mathbf{Z}_{L}=\operatorname{Re}\left\{\mathbf{V}_{F}\right\}+j \operatorname{Im}\left\{\mathbf{V}_{F}\right\}
$$

where $\mathbf{Z}_{L}$ is the total impedance of the considered line, and $\mathbf{D}_{R}$ is the per-unit value of the fault location.

Additionally, the currents $\mathbf{I}_{R F}$ at line section $F R$ and $\mathbf{I}_{S F}$ at line section $S F$ also equal the currents measured on receiving and sending ends (ignored shunt capacitance), respectively. Thus, the fault current $\mathbf{I}_{F}=\mathbf{I}_{R F}+\mathbf{I}_{S F}$ can also be obtained as

$$
\begin{aligned}
\mathbf{I}_{F} & =\mathbf{I}_{R F}+\mathbf{I}_{S F} \\
& =\mathbf{I}_{S}+\mathbf{I}_{R} \\
& =\operatorname{Re}\left\{\mathbf{I}_{F}\right\}+j \operatorname{Im}\left\{\mathbf{I}_{F}\right\} .
\end{aligned}
$$

Therefore, the measured data $\left(\mathbf{V}_{S}, \mathbf{I}_{S}\right)$ and $\left(\mathbf{V}_{R}, \mathbf{I}_{R}\right)$ and (1) can be used to calculate the $\mathbf{V}_{F}$ and $\mathbf{I}_{F}$, i.e., by substituting (2) and (3) into (1), giving

$$
\operatorname{Re}\left\{\mathbf{V}_{F}\right\} \times \operatorname{Im}\left\{\mathbf{I}_{F}\right\}=\operatorname{Re}\left\{\mathbf{I}_{F}\right\} \times \operatorname{Im}\left\{\mathbf{V}_{F}\right\} .
$$

Notably, the only unknown variable in the above equation is the p.u. distance $\mathbf{D}_{R}$. The series device model is not used in deriving (4). Therefore, the per-unit fault location $\mathbf{D}_{R}$ is easily calculated and the series compensation device model is not needed.

Furthermore, when the fault occurs on the left-hand side of the series devices, the reference point on $x=L$ can be intentionally changed, and the following relationships can be substituted into (4):

$$
\mathbf{V}_{S}=\mathbf{V}_{R}, \mathbf{V}_{R}=\mathbf{V}_{S}, \mathbf{I}_{S}=-\mathbf{I}_{R} \text { and } \mathbf{I}_{R}=-\mathbf{I}_{S} .
$$

The above substitution makes it easy to obtain a new per-unit fault location (denoted as $\mathbf{D}^{\prime}$ ) respective to the reference $\mathbf{x}=$ L. When $x=0$ is taken as the reference point, the final per-unit fault location can be computed from $\mathrm{D}_{L}=1-\mathrm{D}^{\prime}$.

So far, the proposed scheme has only generated two values of $\mathrm{D}_{R}$ and $\mathrm{D}_{L}$, and which one is the exact fault location remains undetermined. A skillful selecting algorithm that can easily resolve the mentioned problem will be overlooked here and dealt with later.

\section{Three-Phase Case • With Shunt Capacitance}

Since this case considers the shunt capacitance of the line, the currents $\mathbf{I}_{R F}$ and $\mathbf{I}_{S F}$ entering the fault point $F$, as indicated in Fig. 3, will not equal the currents $\mathbf{I}_{R}$ and $\mathbf{I}_{S}$ as measured at the receiving and sending ends, respectively. The distributed model of the long distance transmission line can be used to calculate these currents. However, the current $\mathbf{I}_{S F}$ can't be calculated with the transmission line model, since the voltage on the right-hand side of series compensated device is unknown. Thus, the relation of (3) is difficult to achieve and the proposed algorithm cannot be directly applied in this case.

Applying the idea mentioned above to a three-phase transmission line with shunt capacitance, the proposed fault location algorithm must be modified and extended to a two-step algorithm - the prelocation and correction steps. The prelocation 
step is to calculate feasible initial fault location, providing an initial value close to the correct fault location. Then, the correction algorithm is applied to calculate the correct fault location, meaning the model of the series compensated device is still not needed.

Now, let Fig. 3 also represent a one-line-diagram of the three-phase transposed transmission line, which consists of phase $a, b, c$ and $a$ ground wires. Subscripts $S$ and $R$ label the sending and receiving ends of transmission line, respectively. Fig. 3 displays that the quantities at each end are all vectors of phase voltages and currents.

The voltages and currents $x(\mathrm{~km})$ away from the receiving end are related through partial differential equations [18]:

$$
\begin{aligned}
& \frac{\partial \mathbf{V}}{\partial \mathbf{x}}=\mathbf{R I}+\mathbf{L} \frac{\partial \mathbf{I}}{\partial \mathbf{t}} \\
& \frac{\partial \mathbf{I}}{\partial \mathbf{x}}=\mathbf{G} \mathbf{V}+\mathbf{C} \frac{\partial \mathbf{V}}{\partial \mathbf{t}}
\end{aligned}
$$

where both $\mathbf{V}$ and $\mathbf{I}$ are $3 \times 1$ vectors. $\mathbf{R}, \mathbf{L}, \mathbf{G}$ and $\mathbf{C}$ are all $3 \times 3$ transposed line parameters matrices with similar forms, such as

$$
\mathbf{L}=\left[\begin{array}{ccc}
\mathbf{L}_{S} & \mathbf{L}_{M} & \mathbf{L}_{M} \\
\mathbf{L}_{M} & \mathbf{L}_{S} & \mathbf{L}_{M} \\
\mathbf{L}_{M} & \mathbf{L}_{M} & \mathbf{L}_{S}
\end{array}\right]
$$

Under sinusoidal steady-state condition, (6) can be rewritten as

$$
\begin{aligned}
& \frac{\partial \mathbf{V}}{\partial \mathbf{x}}=\mathbf{Z I} \\
& \frac{\partial \mathbf{I}}{\partial \mathbf{x}}=\mathbf{Y} \mathbf{V}
\end{aligned}
$$

where $\mathbf{Z}=\mathbf{R}+j w \mathbf{L}$ and $\mathbf{Y}=\mathbf{G}+j w \mathbf{C}$.

To decouple phase quantities, this work uses the symmetric component transform [18] as follows:

$$
\begin{aligned}
& {\left[\begin{array}{l}
\mathbf{V}_{a} \\
\mathbf{V}_{b} \\
\mathbf{V}_{c}
\end{array}\right]=\mathbf{T}\left[\begin{array}{l}
\mathbf{V}_{0} \\
\mathbf{V}_{1} \\
\mathbf{V}_{2}
\end{array}\right]} \\
& {\left[\begin{array}{l}
\mathbf{I}_{a} \\
\mathbf{I}_{b} \\
\mathbf{I}_{c}
\end{array}\right]=\mathbf{T}\left[\begin{array}{l}
\mathbf{I}_{0} \\
\mathbf{I}_{1} \\
\mathbf{I}_{2}
\end{array}\right]}
\end{aligned}
$$

where 0,1 , and 2 represent the symmetric components of the voltage and current quantities, and the sequence transformation matrix is as follows:

$$
\mathbf{T}=\left[\begin{array}{ccc}
1 & 1 & 1 \\
1 & \alpha^{2} & \alpha \\
1 & \alpha & \alpha^{2}
\end{array}\right]
$$

where $\alpha=1 \angle 120^{\circ}$. Substituting (9) and (10) into (8) gives the following sequence equations:

$$
\begin{aligned}
\frac{\partial \mathbf{V}_{012}}{\partial \mathbf{x}} & =\mathbf{Z}_{012} \mathbf{I}_{012} \\
\frac{\partial \mathbf{I}_{012}}{\partial \mathbf{x}} & =\mathbf{Y}_{012} \mathbf{V}_{012}
\end{aligned}
$$

where $\mathbf{Z}_{012}$ and $\mathbf{Y}_{012}$ are the sequence impedance and admittance matrix, respectively. The matrices of $\mathbf{Z}_{012}$ and $\mathbf{Y}_{012}$ are all diagonal matrices, and the diagonal entries of matrices $\mathbf{Z}_{012}$ and $\mathbf{Y}_{012}$ are $\left(\mathbf{Z}_{0}, \mathbf{Z}_{1}, \mathbf{Z}_{2}\right)$ and $\left(\mathbf{Y}_{0}, \mathbf{Y}_{1}, \mathbf{Y}_{2}\right)$, respectively. Thus, (11) represents three decoupled sequence systems whose solutions can be written as

$$
\begin{aligned}
\mathbf{V}_{\mathbf{m}} & =\mathbf{A}_{\mathbf{m}} \exp \left(\gamma_{\mathbf{m}} \mathbf{x}\right)+\mathbf{B}_{\mathbf{m}} \exp \left(-\gamma_{\mathbf{m}} \mathbf{x}\right) \\
\mathbf{I}_{\mathbf{m}} & =\left[\mathbf{A}_{\mathbf{m}} \exp \left(\gamma_{\mathbf{m}} \mathbf{x}\right)+\mathbf{B}_{\mathbf{m}} \exp \left(-\gamma_{\mathbf{m}} \mathbf{x}\right)\right] / \mathbf{Z}_{\mathbf{c m}}
\end{aligned}
$$

where the subscript $\mathbf{m}$ denotes 0,1 and 2 sequence variables, $\mathbf{Z}_{\mathbf{c m}}=\sqrt{\mathbf{Z}_{\mathbf{m}}} / \mathbf{Y}_{\mathbf{m}}$ is the characteristic impedance, and $\gamma_{\mathbf{m}}=\sqrt{\mathbf{Z}_{\mathbf{m}} \mathbf{Y}_{\mathbf{m}}}$ is the propagation constant. Meanwhile, the constants $\mathbf{A}_{m}$ and $\mathbf{B}_{m}$ can be determined by the boundary conditions of voltages and currents measured at both ends of the line.

Since the fault location with respect to the series compensation device is unknown prior to fault location estimation, the proposed fault location algorithm will first calculate two locations via subroutines 1 and 2 simultaneously. These two faults are assumed to occur at right- and left-hand sides of the series device, respectively. Then, this work follows the approach proposed by Saha et al. [4] to develop a skillful selector for exactly distinguishing the true fault site. The following section explains this skillful selector.

\section{Subroutine $1 \bullet$ Fault Location for the Right Side of the Series Compensation Device}

The description of subroutine 1 is divided between the prelocation and correction steps.

Prelocation Step: The basic concept in the simple illustrative cases is extended and modified to become the prelocation step. This study discusses the prelocation algorithm with respect to two types of faults and is easily extendible to other fault types.

1) Three Phase Shorted Fault Case: Herein, we only use the positive sequence component. The equations of fault voltage and fault current on the fault location $x=\mathrm{D}_{R}$ can be expressed as follows:

$$
\begin{aligned}
\mathbf{V}_{F}= & \mathbf{V}_{F 1} \\
= & \frac{\mathbf{V}_{R 1}+\mathbf{I}_{R 1} \mathbf{Z}_{C 1}}{2} \exp \left(\gamma_{1} \mathbf{D}_{R} \mathbf{L}\right) \\
& +\frac{\mathbf{V}_{R 1}-\mathbf{I}_{R 1} \mathbf{Z}_{C 1}}{2} \exp \left(-\gamma_{1} \mathbf{D}_{R} \mathbf{L}\right) \\
= & \operatorname{Re}\left\{\mathbf{V}_{F 1}\right\}+j \operatorname{Im}\left\{\mathbf{V}_{F 1}\right\} \\
\mathbf{I}_{F}= & \mathbf{I}_{F 1} \\
= & \mathbf{I}_{R F 1}+\mathbf{I}_{S F 1} \\
= & \frac{\mathbf{V}_{R 1}+\mathbf{I}_{R 1} \mathbf{Z}_{C 1}}{2} \exp \left(\gamma_{1} \mathbf{D}_{R} L\right) \\
& \left.-\frac{\mathbf{V}_{R 1}-\mathbf{I}_{R 1} \mathbf{Z}_{C 1}}{2} \exp \left(-\gamma_{1} \mathbf{D}_{R} L\right)\right] \mathbf{Z}_{C 1}^{-1} \\
& +\left[\frac{\mathbf{V}_{S 1}+\mathbf{I}_{S 1} \mathbf{Z}_{C 1}}{2 \exp \left(\gamma_{1} L\right)} \exp \left(\gamma_{1} \mathbf{D}_{R} L\right)\right. \\
& \left.-\frac{\mathbf{V}_{S 1}-\mathbf{I}_{S 1} \mathbf{Z}_{C 1}}{2 \exp \left(\gamma_{1} L\right)} \exp \left(-\gamma_{1} \mathbf{D}_{R} L\right)\right] \mathbf{Z}_{C 1}^{-1} \\
= & \operatorname{Re}\left\{\mathbf{I}_{F 1}\right\}+j \operatorname{Im}\left\{\mathbf{I}_{F 1}\right\} .
\end{aligned}
$$


Thus, the relation of (1) can be rewritten as

$$
\operatorname{Arg}\left(\mathbf{V}_{F 1}\right)=\operatorname{Arg}\left(\mathbf{I}_{F 1}\right) .
$$

Using the same treatment with single-phase case, the per-unit initial fault location $\mathbf{D}_{R}$ can then be easily calculated by the following equation:

$$
\operatorname{Re}\left\{\mathbf{V}_{F 1}\right\} \times \operatorname{Im}\left\{\mathbf{I}_{F 1}\right\}=\operatorname{Re}\left\{\mathbf{I}_{F 1}\right\} \times \operatorname{Im}\left\{\mathbf{V}_{F 1}\right\} .
$$

2) Single Line to Ground Fault Case: To simplify the expression, the following two functions $F_{V}$ and $F_{I}$ can be defined as follows:

$$
\begin{aligned}
F_{V}\left(V_{R}, I_{R}, Z_{C}, \gamma, D_{R}\right) \\
=\frac{V_{R}+I_{R} Z_{C}}{2} \exp \left(\gamma D_{R} L\right) \\
\quad+\frac{V_{R}-I_{R} Z_{C}}{2} \exp \left(-\gamma D_{R} L\right) \\
F_{I}\left(V_{S}, I_{S}, V_{R}, I_{R}, Z_{C}, \gamma, D_{R}\right) \\
=\left[\frac{V_{R 1}+I_{R 1} Z_{C 1}}{2} \exp \left(\gamma D_{R} L\right)\right. \\
\left.\quad-\frac{V_{R 1}-I_{R 1} Z_{C 1}}{2} \exp \left(-\gamma_{1} D_{R} L\right)\right] Z_{C}^{-1} \\
\quad+\left[\frac{V_{S}+I_{S} Z_{C}}{2 \exp (\gamma L)} \exp \left(\gamma D_{R} L\right)\right. \\
\left.\quad-\frac{V_{S}-I_{S} Z_{C}}{2 \exp (\gamma L)} \exp \left(-\gamma D_{R} L\right)\right] Z_{C}^{-1} .
\end{aligned}
$$

The derivation mentioned above can be directly applied to this fault case. Meanwhile, the relation between fault voltage and current at the fault location $x=\mathbf{D}_{R} L$ can be expressed as follows:

$$
\begin{aligned}
\mathbf{V}_{F}= & \mathbf{V}_{F 0}+\mathbf{V}_{F 1}+\mathbf{V}_{F 2} \\
= & F_{V}\left(\mathbf{V}_{R 0}, \mathbf{I}_{R 0}, \mathbf{Z}_{C 0}, \gamma_{0}, \mathbf{D}_{R}\right) \\
& +F_{V}\left(\mathbf{V}_{R 1}, \mathbf{I}_{R 1}, \mathbf{Z}_{C 1}, \gamma_{1}, \mathbf{D}_{R}\right) \\
& +F_{V}\left(\mathbf{V}_{R 2}, \mathbf{I}_{R 2}, \mathbf{Z}_{C 2}, \gamma_{2}, \mathbf{D}_{R}\right) \\
= & \operatorname{Re}\left\{\mathbf{V}_{F 0}+\mathbf{V}_{F 1}+\mathbf{V}_{F 2}\right\} \\
& +j \operatorname{Im}\left\{\mathbf{V}_{F 0}+\mathbf{V}_{F 1}+\mathbf{V}_{F 2}\right\} \\
\mathbf{I}_{F}= & \left(\mathbf{I}_{F 0}+\mathbf{I}_{F 1}+\mathbf{I}_{F 2}\right) / 3 \\
= & {\left[F_{I}\left(\mathbf{V}_{S 0}, \mathbf{I}_{S 0}, \mathbf{V}_{R 0}, \mathbf{I}_{R 0}, \mathbf{Z}_{C 0}, \gamma_{0}, \mathbf{D}_{R}\right)\right.} \\
& +F_{I}\left(\mathbf{V}_{S 1}, \mathbf{I}_{S 1}, \mathbf{V}_{R 1}, \mathbf{I}_{R 1}, \mathbf{Z}_{C 1}, \gamma_{1}, \mathbf{D}_{R}\right) \\
& \left.+F_{I}\left(\mathbf{V}_{S 2}, \mathbf{I}_{S 2}, \mathbf{V}_{R 2}, \mathbf{I}_{R 2}, \mathbf{Z}_{C 2}, \gamma_{2}, \mathbf{D}_{R}\right)\right] / 3 \\
= & \operatorname{Re}\left\{\left(\mathbf{I}_{F 0}+\mathbf{I}_{F 1}+\mathbf{I}_{F 2}\right) / 3\right\} \\
& +j \operatorname{Im}\left\{\left(\mathbf{I}_{F 0}+\mathbf{I}_{F 1}+\mathbf{I}_{F 2}\right) / 3\right\} .
\end{aligned}
$$

The equivalent network of fault analysis reveals that the relation of (1) can be expressed as

$$
\operatorname{Arg}\left(\mathbf{V}_{F 0}+\mathbf{V}_{F 1}+\mathbf{V}_{F 2}\right)=\operatorname{Arg}\left[\left(\mathbf{I}_{F 0}+\mathbf{I}_{F 1}+\mathbf{I}_{F 2}\right) / 3\right]
$$

where the average value of three sequence current components is adopted as fault path current. From our experience, this can promote the accuracy of fault location. Substituting (17) and (18) into (19), gives

$$
\begin{aligned}
& \operatorname{Re}\left\{\mathbf{V}_{F 0}+\mathbf{V}_{F 1}+\mathbf{V}_{F 2}\right\} \times \operatorname{Im}\left\{\left(\mathbf{I}_{F 0}+\mathbf{I}_{F 1}+\mathbf{I}_{F 2}\right) / 3\right\} \\
& =\operatorname{Re}\left\{\left(\mathbf{I}_{F 0}+\mathbf{I}_{F 1}+\mathbf{I}_{F 2}\right) / 3\right\} \times \operatorname{Im}\left\{\mathbf{V}_{F 0}+\mathbf{V}_{F 1}+\mathbf{V}_{F 2}\right\}
\end{aligned}
$$

This equation allows easy calculation of the per-unit initial fault location $\mathrm{D}_{R}$.

Correction Step: Since the voltage $\mathbf{V}_{S E R}$ of right-hand side of the series compensated device in Fig. 4 is unknown (that is, the voltage drop of series compensated device is unknown), the shunt charging current between the series compensated device and the fault end point is also unknown. Thus, when the proposed fault location algorithm is directly applied to transmission line with shunt capacitance, the main error will be induced from the unknown voltage drop of series compensation device. This section proposes a novel correction algorithm to adjust the prelocation result to a correct solution and to calculate correct voltage drop of the series compensation device without using the series device model. The solution to the problem is described as follows.

Herein, $\mathbf{V}_{S E R n}$ is used to represent the $n$th iteration value of $\mathbf{V}_{S E R}$, where $n=0,1,2, \ldots$ Initially, $(n=0)$, the prelocation step ignores the difference between $\mathbf{V}_{S E R O}$ and $\mathbf{V}_{S E L}$ (the voltage of left-hand side of the series compensated device) and the algorithm computes the fault location $\mathbf{D}_{0}$ and fault end voltage $\mathbf{V}_{F 0}$. These two computed values then serve as feasible initial values in the correction step.

Fig. 4 indicates that the transmission line is modeled as a two-port hyperbolic $\pi$-model between the fault location end and the series compensated device right-hand side, i.e.,

$$
\begin{aligned}
\mathbf{Z}_{E} & =\mathbf{Z}_{c} \sinh (\gamma l) \\
\mathbf{Y} / 2 & =1 / \mathbf{Z}_{c} \tanh (\gamma l / 2)
\end{aligned}
$$

where $l=\left(q-\mathbf{D}_{0}\right) L(\mathrm{~km})$ is the line length of the $\pi$-model transmission line.

Since the series compensation device does not influence the current flowing through it, the current $\mathbf{I}_{S E L}$ flow into the left-hand side of series device will equal the current $\mathbf{I}_{S E R}$ flow out from the right-hand side of the series device. Thus, the two-port circuit enclosed by dashed line has two input parameters, one is the correct input current $\mathbf{I}_{S E R}$ and the other is the voltage $\mathbf{V}_{F 0}$ computed from the prelocation step. The basic circuit theory indicates that the input voltage $\mathbf{V}_{S E R 1}$ (the second iterative value) of the two-port circuit can be easily calculated as

$$
\mathbf{V}_{S E R 1}=\mathbf{Z}_{E} /\left(1+\mathbf{Y} / 2 \times \mathbf{Z}_{E}\right)\left(\mathbf{I}_{S E R}+\mathbf{V}_{F 0} / \mathbf{Z}_{E}\right) .
$$

Therefore, a new fault location problem can be constructed. The transmission line being considered is located between the two terminals of $\left(\mathbf{V}_{S E R 1}, \mathbf{I}_{S E R}\right),\left(\mathbf{V}_{R}, \mathbf{I}_{R}\right)$, enclosed by the dotted line in Fig. 4. The line length of the new system is $q L$ $(\mathrm{km})$ and the transmission line between these two terminals has no series compensated devices. $\mathbf{V}_{S}=\mathbf{V}_{S E R 1}, \mathbf{I}_{S}=\mathbf{I}_{S E R}$ can be substituted into the prelocation algorithm proposed in the previous section to calculate a new fault location $\mathbf{D}_{1}$ and fault end voltage $\mathbf{V}_{F 1}$. These two parameters allow the third iterative value of voltage $\mathbf{V}_{S E R n}$ (i.e., $\mathbf{V}_{S E R 2}$ ) to be once again 


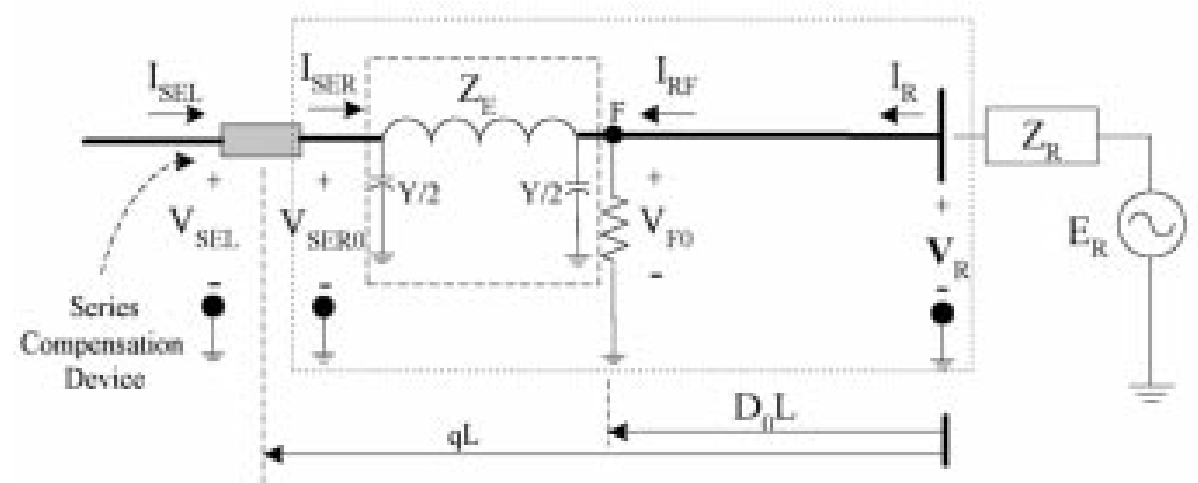

Fig. 4. Two-Port circuit for correction step.

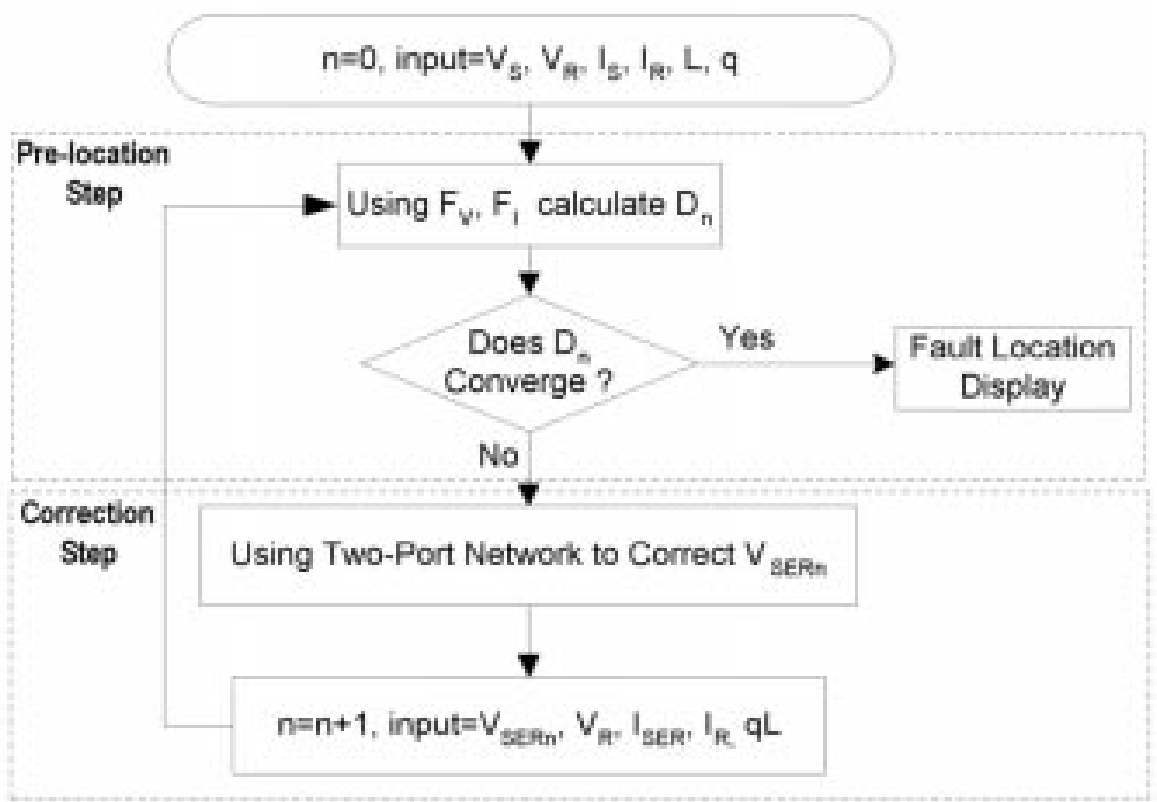

Fig. 5. Flow-chart of two-steps fault location algorithm.

computed from the iterative formulas (21) and (22). The proposed algorithm will repeat the procedure until fault $\mathrm{D}$ is accurately located. This investigation reveals that the proposed algorithm usually takes $3 \sim 4$ iterations to accurately locate a fault. Thus, the fault location for a series compensated transmission line is straightforward using the proposed algorithm and the device model is still not required. The flowchart in Fig. 5 describes the prelocation/correction two-step algorithm.

\section{Subroutine $2 \bullet$ Fault Location for the Left Side of the Series Compensation Device}

When the fault occurs on the left side of the series devices, the reference point on $x=L$ can be deliberately changed, substituting the following relationships:

$$
\mathbf{V}_{S}=\mathbf{V}_{R}, \mathbf{V}_{R}=\mathbf{V}_{S}, \mathbf{I}_{S}=-\mathbf{I}_{R} \text { and } \mathbf{I}_{R}=-\mathbf{I}_{S}
$$

into the above two-step iterative formulas, and thus obtaining a new per-unit fault location (denoted as $\mathbf{D}^{\prime}$ ) in relation to the reference $\mathbf{x}=\mathbf{L}$. When $x=0$ is taken as the reference point, the final per-unit fault location can be computed from $\mathrm{D}_{L}=$ $1-\mathbf{D}^{\prime}$.

\section{Fault Selector}

According to our results, the fault location calculated on the incorrect side may sometimes have no unique converged solution. Instead, solutions will follow a large oscillating trajectory. Additionally, fault location calculated on the incorrect side will become divergent and will sometimes have no solution. Thus, selecting between two fault location solutions (calculated from subroutine 1 and subroutine 2 ) in these cases is simply a matter of choosing the one with less oscillation or more convergence. Furthermore, when the calculated fault locations of both $\mathrm{D}_{R}$ and $\mathbf{D}_{L}$ are all located on the same side of the series device, the simple approach from [7] can be used to select the correct fault location.

While the estimated fault location can discriminate between correct and incorrect sites, it still may be fail for some special faulted situations. This work thus proposes a skillful selector for 
selecting the correct fault site with respect to the series compensation device.

For systematically selecting the true fault location this section proposes a skillful selection algorithm. The proposed two-step fault location algorithm can calculate the voltage of $\mathbf{V}_{S E R}$ in Fig. 4. Additionally, the voltage $\mathbf{V}_{S E L}$ of the point just in front of the series device is also easily calculated from the transmission line equation. Thus, the voltage drop $\Delta \mathbf{V}_{\mathbf{S E}}$ of the series compensation device can be calculated by $\mathbf{V}_{S E L}-\mathbf{V}_{S E R}$. The equivalent impedance of the series compensation device can be calculated as

$$
\mathbf{Z}_{S E}=\Delta \mathbf{V}_{\mathbf{S E}} / \mathbf{I}_{\mathbf{S E R}}=\mathbf{R}_{\mathbf{S E}}+\mathbf{j} \mathbf{Z}_{\mathbf{S E}} \cdot
$$

If the estimated result of the fault location is on the correct side, the $\mathbf{R}_{S E}$ will be a positive value (obeying the law of physics). Otherwise, the $\mathbf{R}_{S E}$ will be negative (violating the law of physics) for the incorrect side estimation. For example, when $b-c$ line-to-line fault occurs on the right side of the series device, the $\mathbf{R}_{S E R}$ of $b$-phase and $c$-phase calculated from subroutine 1 will be positive. Otherwise, when using subroutine 2, the calculated $\mathbf{R}_{S E L}$ of the $b$ and $c$-phases will be negative. Thus, the selecting criteria can be stated as:

The fault location of the estimated set $\left[D_{R}, D_{L}\right]$ that corresponds to positive $R_{S E}$ is selected as the correct solution.

The selection criteria can be easily demonstrated by the simplified model of short distance transmission line and will be presented in Appendix B.

The above-mentioned selection criteria can also be easily applied to short distance transmission line cases that ignore the shunt capacitor charging current. In this case, the voltages $\mathbf{V}_{S E L}$ and $\mathbf{V}_{S E R}$ can be easily calculated by $K V L$, and the voltage drop of the series compensation device also can be calculated. Thus, the same selecting algorithm can also be easily applied in this case.

Compared with the selection algorithm proposed in [4], the selection criteria proposed here have more physical insights. Furthermore, the proposed selection criteria in this paper can be used to double check fault type in the next section.

\section{E. Double-Check of Fault Type}

This study assumes that the fault type is input from the other diagnostic block. However, the fault type diagnostic block may produce incorrect output in some cases. To identify these situations, this section suggests a method for double-checking.

When the equivalent impedance $\mathbf{Z}_{S E}$ of series devices has been calculated, the $\mathbf{Z}_{S E}$ of the three-phase series device can serve as the three double-checking indices for the input fault type. For example, when three-phase shorted fault occurs, the fault current flows through the three-phase series device simultaneously. Thus, the three-phase equivalent impedance of all the $\mathbf{Z}_{S E}$ must possess the same impedance characteristic, that is, the MOV of the $\mathbf{Z}_{S E}$ all conduct (while all the three-phase of series device possess large resistance characteristic), or else the three-phase series devices enter the bypass mode (while the $\mathbf{Z}_{S E}$ are all inductive). Therefore, the $\mathbf{Z}_{S E}$ can be easily used as three indices of the fault type double-check to check whether the impedance characteristics of the three-phase $\mathbf{Z}_{S E}$ coincide with

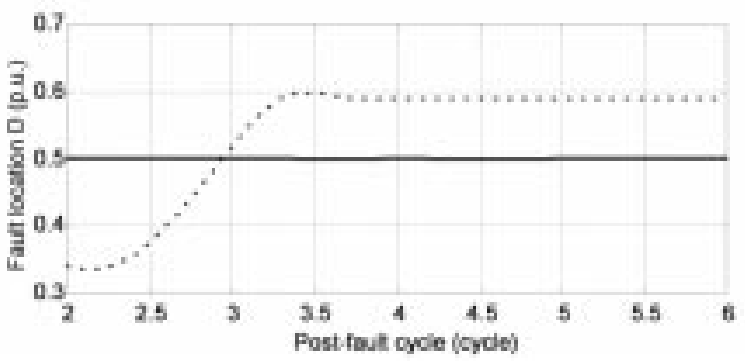

Fig. 6. Fault Location of $\mathbf{D}_{R}$ (solid line) and $\mathbf{D}_{L}$ (dotted line).

the conditions of the input fault type. If the impedance characteristics do not match these conditions, a signal can be issued to the fault type diagnostic block to request other fault type.

\section{Performance Evaluation}

\section{A. Algorithm Test}

This section evaluates the fault location algorithms proposed here using some case studies. The simulation sample considered is a $300-\mathrm{km} 345-\mathrm{kV}$ transmission line compensated by thyristor controlled switched capacitance (TCSC) with a compensation degree of 70\%. All the systems are modeled by EMTP. The phasors are estimated using the SDFT [14], [15] filtering algorithm working at 32 samples per cycle. The total simulation time is $200 \mathrm{~ms}$ and the error of the fault location is expressed in terms of percentage of total line length. Appendix A presents the parameters of the sample system. As is well known, the different protection function design of TCSC will introduce different type of disturbances into compensation voltage. Thus, the protection functions of TCSC must be considered when evaluating the performance of the proposed fault location algorithm. For convenience, this investigation adopts the protection functions presented in [4].

Case 1: Large Fault Current $\mathbf{I}_{F}$ Cases $\bullet$ Basic Tests: In this case, the TCSC device is installed near the midpoint at $135 \mathrm{~km}$ ( $q=0.45$ p.u.) away from the receiving end of the protected line. Assume that a three-phase ground fault occurs at $150 \mathrm{~km}$ ( $\mathbf{D}=0.5$ p.u.). The fault resistance is set as $1(\mathrm{Ohm})$.

The fault locations $\mathbf{D}_{R}$ and $\mathbf{D}_{L}$ are computed from subroutines one and two simultaneously. Meanwhile, Fig. 6 plots the estimations of $\mathbf{D}_{R}$ and $\mathbf{D}_{L}$. At 2.5 cycles after fault inception, the proposed algorithms provide the following results.

1) Only one prelocation algorithm is used:

$$
\mathrm{D}_{R}=0.3683 \text { (р.u.), } \mathrm{D}_{L}=0.5001 \text { (р.u.). }
$$

2) Two-step iteration algorithm is used:

$$
\mathrm{D}_{R}=0.3682 \text { (p.u.), } \mathrm{D}_{L}=0.50008 \text { (p.u.). }
$$

Both the prelocation and two-step iteration algorithms can provide accurate fault location in this case. Fig. 6 clearly displays that the incorrect fault location $\mathrm{D}_{R}$ will contain considerable oscillation in five simulation cycles. Additionally, the equivalent resistance of $\mathbf{R}_{S E R}$ and $\mathbf{R}_{S E L}$ also shown in Fig. 7(a) and (b) respectively. One can note that the $\mathbf{R}_{S E R}$ is negative. Therefore, one can easily choose $\mathrm{D}=\mathrm{D}_{L}=0.50008$ as the correct solution.

Fig. 8 compares fault location calculation using DFT and SDFT [13]-[16] filters. Obviously, the exponential decay of 
(a)

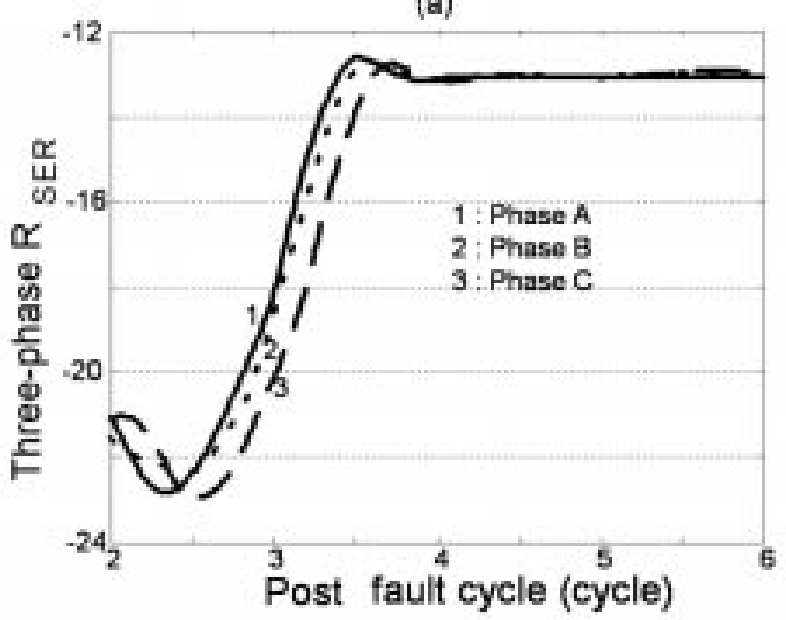

(b)

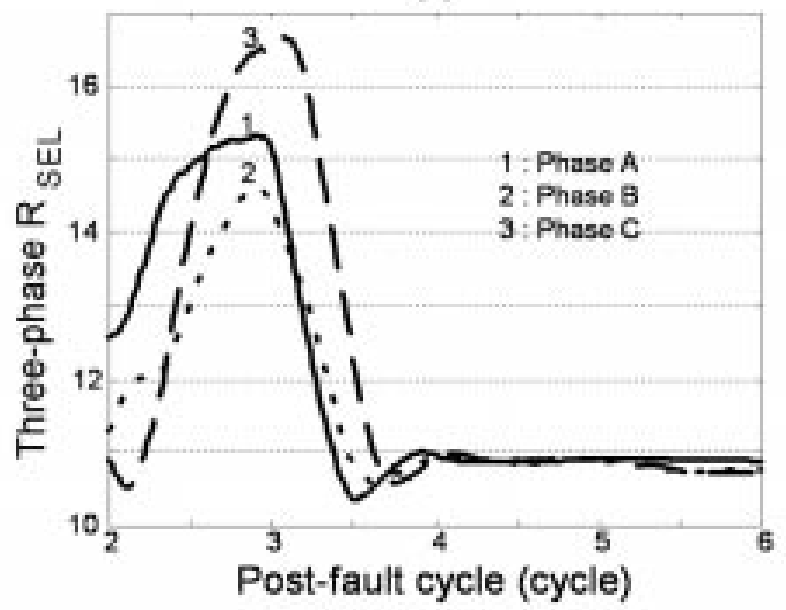

Fig. 7. (a) Equivalent resistance of $\mathbf{R}_{S E R}$. (b) Equivalent resistance of $\mathbf{R}_{S E L}$.

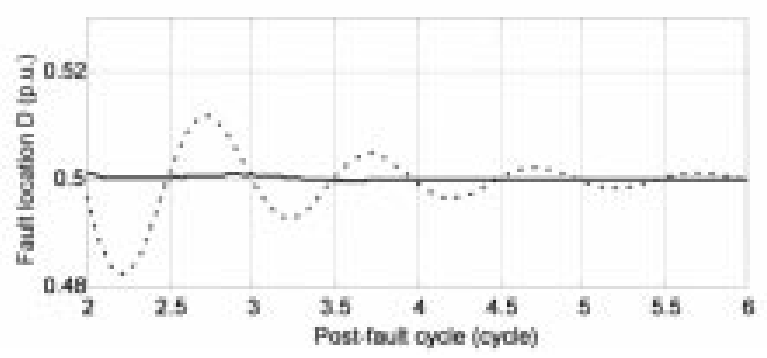

Fig. 8. Fault location calculation by SDFT (solid line) and DFT (dotted line)

dc-offset in the fault current and voltage signals will markedly influence fault location when fault location is calculated by DFT. When the fault location result is calculated using SDFT, then the calculated location would not have the same slow damping as in the DFT results. Instead, the calculated fault location converges very fast and an accurate location is easily and quickly achieved.

Fig. 9 presents the detailed waveform of TCR currents, MOV currents and line currents in TCSC device before and after a fault occurs. The TCR switches to the block mode and the MOV begins to bypass the fault current when the fault starts to occur at

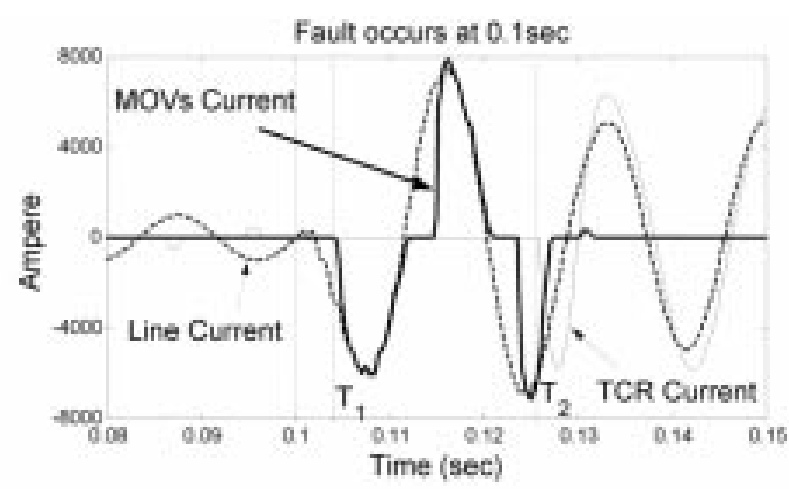

Fig. 9. Current waveform in TCSC device.

$t=T_{1}$, since the overvoltage condition is detected by the TCSC controller. The TCR changes to bypass mode at $t=T_{2}$, since the energy absorbs in the MOV is exceed its limitation. Notably, the proposed algorithm can still easily provide the accurate fault location result, whatever the complexity of the TCSC protection function operates.

Case 2: Small Fault Current $\mathbf{I}_{F}$ Cases $\bullet$ Correction Step Tests: In this case, the TCSC device is installed near the receiving end bus at $15 \mathrm{~km}(q=0.05$ p.u. $)$ and a single line to ground fault occurs at $285 \mathrm{~km}(\mathrm{D}=0.95$ p.u. $)$. The fault resistance assumes $100(\mathrm{Ohm})$.

The fault locations $\mathbf{D}_{R}$ and $\mathbf{D}_{L}$, calculated from subroutines 1 and 2, are shown, respectively, as follows.

1) After only one prelocation step

$$
\mathrm{D}_{R}=1.6733 \text { (p.u.), } \mathrm{D}_{L}=0.9869 \text { (p.u.). }
$$

2) After three times two-step iteration algorithm

$$
\mathrm{D}_{R}=1.0112 \text { (p.u.), } \mathrm{D}_{L}=0.9503 \text { (p.u.). }
$$

When selecting between the above two locations of $\mathbf{D}_{R}$ and $\mathbf{D}_{L}$, the solution of $\mathbf{D}_{R}$ exceeds 1.0 is easily ignored, and the solution $\mathbf{D}_{L}$ is the correct one.

Comparing the above two solutions of the only one prelocation and two-step algorithm, the fault location error is clearly large (error $=3.69 \%$ ) when using only one prelocation step. Additionally, when using the proposed two-step algorithm, the fault location error can be reduced to $0.03 \%$. Thus, the proposed two-step iteration algorithm has been proven as a useful fault location algorithm.

Case 3: Fault Type Double-Check Test: When the fault location is calculated by the proposed two-step iteration algorithm, the input fault type can be double-checked by the proposed double-check algorithm.

In this case, the TCSC device is installed near the midpoint at $135 \mathrm{~km}(q=0.45$ p.u. $)$ and a $b$-phase to $c$-phase line-to-line fault occurs at $240 \mathrm{~km}(\mathrm{D}=0.8$ p.u.). The fault resistance is set as $10(\mathrm{Ohm})$. Assume the fault type input from the fault type diagnostic block is incorrect and given as a three-phase-short fault. The incorrect fault location can still be calculated from the two-step algorithm and the incorrect solutions of $\mathbf{D}_{L}$ and $\mathbf{D}_{R}$ are shown as follows:

$$
\mathrm{D}_{L}=0.5339 \text { (p.u.), } \mathrm{D}_{R}=\text { Divergence. }
$$

Because the divergence result of $\mathbf{D}_{R}$ is easily ignored, the fault location is chosen as $\mathbf{D}=\mathbf{D}_{L}=0.5339$ (p.u.). 
(a)

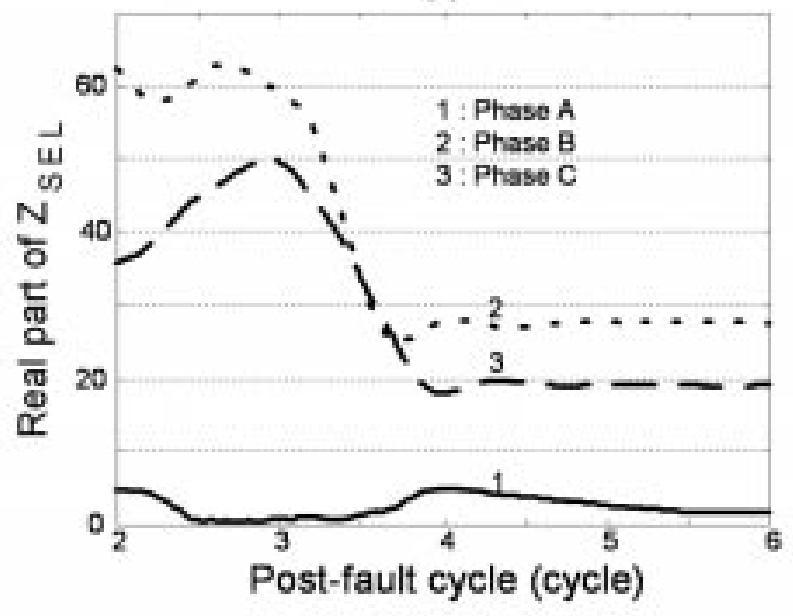

(b)

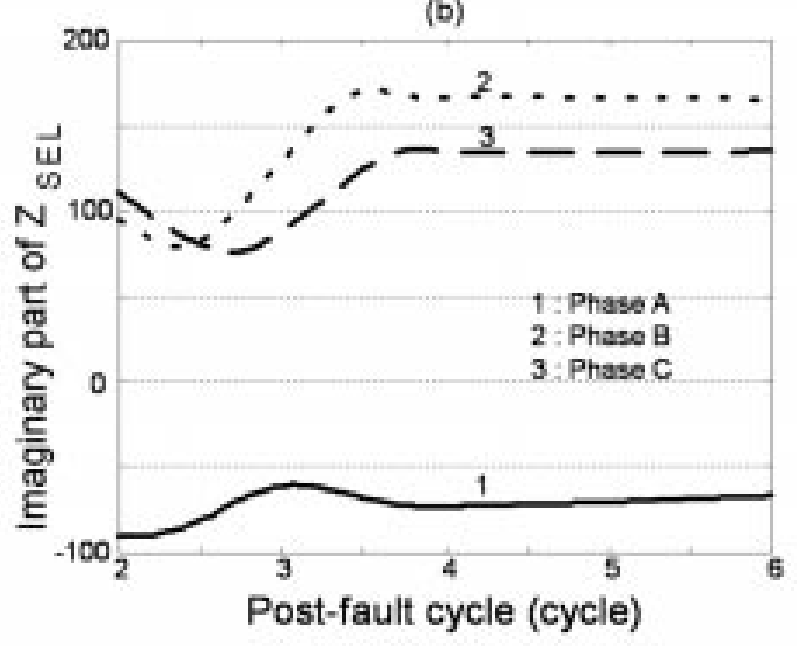

Fig. 10. (a) Real part of three-phase $\mathbf{Z}_{S E}$. (b) Imaginary part of three-phase $\mathbf{Z}_{S E}$.

To double-check the input fault type, the equivalent series impedance calculated from (24) can be used as three indices. Fig. 10(a) and (b), respectively, illustrate the real and imaginary part of three-phase $\mathbf{Z}_{S E}$. Notably, the three-phase equivalent impedance of $\mathbf{Z}_{S E}$ does not possess the three-phase-short fault characteristic; that is, three-phase $\mathbf{Z}_{S E}$ does not have the same impedance characteristic. Actually, the impedance characteristic seems like the $b-c$ line-to-line short fault. Thus, incorrect fault type can easily be discovered. One signal can be sent to the fault type diagnostic block to request new fault type.

In addition, when the input fault type is correct, the fault locations $\mathbf{D}_{L}$ and $\mathbf{D}_{R}$ are shown as follows:

$$
\mathrm{D}_{L}=0.7992 \text { (p.u.), } \mathrm{D}_{R}=0.4023 \text { (p.u.). }
$$

Fig. 11(a) and (b) indicates the $\mathbf{R}_{S E R}$ and $\mathbf{R}_{S E L}$ calculated from subroutines 1 and 2 respectively. Using the proposed selector, the correct fault location is easily chosen as $\mathbf{D}=\mathbf{D}_{L}=$ 0.7992 , since the equivalent resistance $\mathbf{R}_{S E R}$ of subroutine 1 is negative and $\mathbf{R}_{S E L}$ of subroutine 2 is positive. Additionally, Fig. 12 displays the imaginary part of three-phase $\mathbf{Z}_{S E}$ and the real part of three-phase $\mathbf{Z}_{S E}$ is the same as shown in Fig. 11(b). Notably, the three-phase equivalent impedance of $\mathbf{Z}_{S E}$ indeed possess the $b$ - $c$ phase line-to-line fault characteristic; that is, the
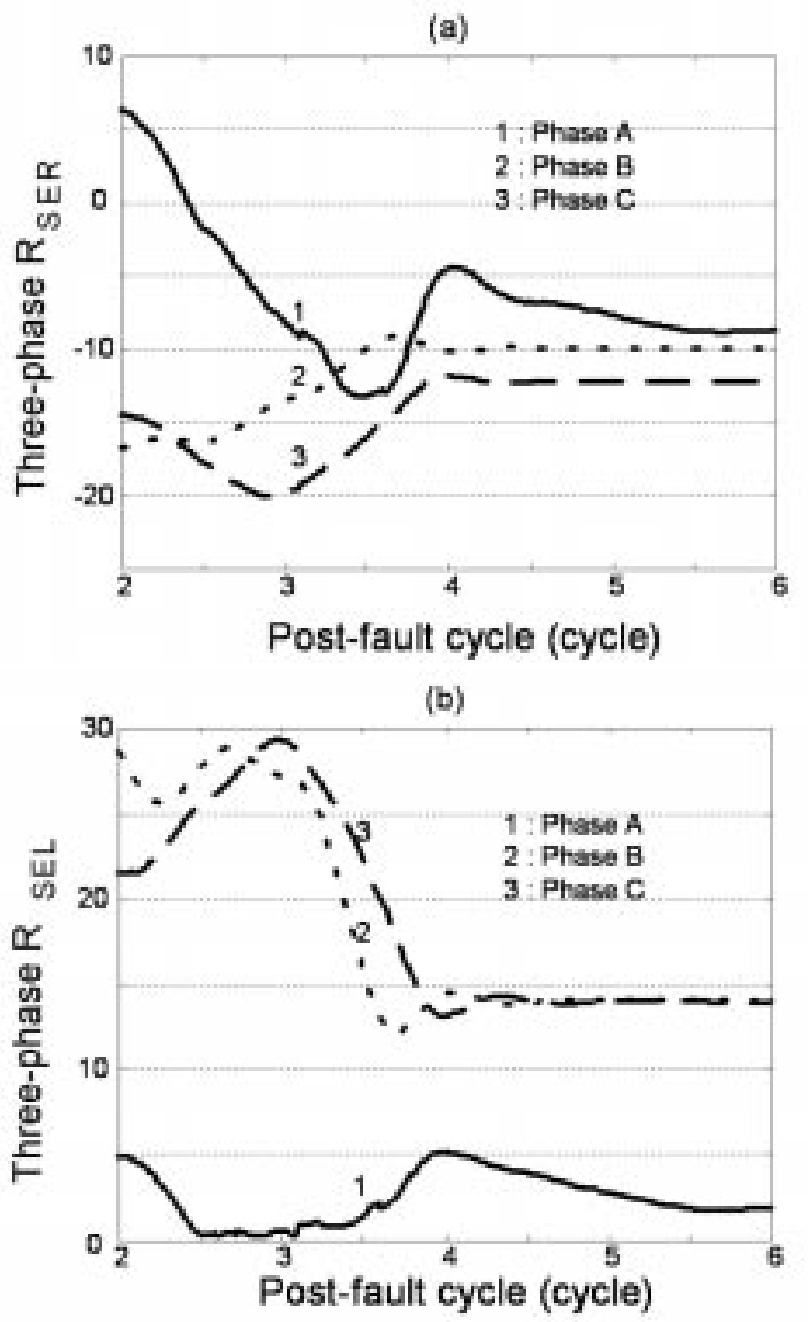

Fig. 11. (a) Equivalent resistance of $\mathbf{R}_{S E R}$; (b) Equivalent resistance of $\mathbf{R}_{S E L}$.

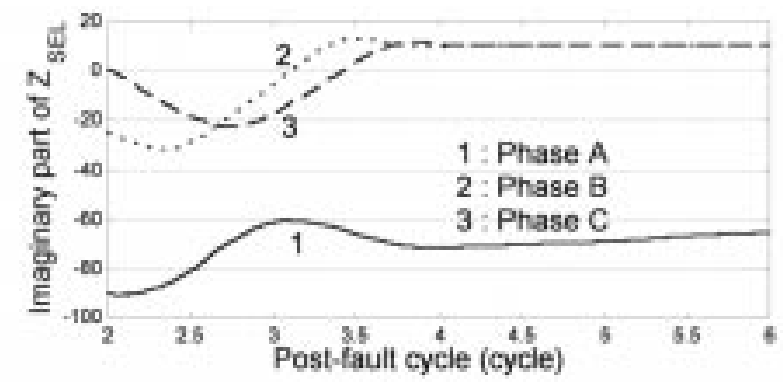

Fig. 12. Imaginary part of three-phase $\mathbf{Z}_{S E}$.

impedance of phase $b$ and $c$ have the same characteristic. Thus, the input fault type is easy to double-check using these $\mathbf{Z}_{S E}$ indices.

\section{B. Statistical Evaluation}

This section evaluates the proposed fault location algorithm with over 500 test cases obtained from the EMTP simulator. It considers different fault types, resistances, locations, and inception angles as statistical tests. It uses the same transmission line and series compensation device data as the previous section. Table I summarizes all of these results. To save space, all 
TABLE I

StatisticAl TESTING OF THE AlgORITHM

\begin{tabular}{|c|c|c|c|c|c|c|}
\hline \multirow{2}{*}{$\begin{array}{l}\text { Fault } \\
\text { Type }\end{array}$} & \multirow{2}{*}{$\mathrm{R}_{\mathrm{F}}$} & \multicolumn{5}{|c|}{ Fault location error $(\%)$} \\
\hline & & $30 \mathrm{~km}$ & $75 \mathrm{~km}$ & $150 \mathrm{~km}$ & $225 \mathrm{~km}$ & $270 \mathrm{~km}$ \\
\hline \multirow{5}{*}{$\begin{array}{c}\text { Three } \\
\text { Phases } \\
\text { To } \\
\text { Ground }\end{array}$} & $0.1 \Omega$ & $\begin{array}{l}\mathbf{a v e}=0.0007 \\
\mathbf{m a x}=0.001\end{array}$ & $\begin{array}{l}\text { ave }=0.001 \\
\max =0.0014\end{array}$ & $\begin{array}{l}\text { ave }=0.0034 \\
\max =0.006\end{array}$ & $\begin{array}{l}\text { ave }=0.0009 \\
\max =0.0019\end{array}$ & $\begin{array}{l}\text { ave }=0.0007 \\
\max =0.0009\end{array}$ \\
\hline & $1 \Omega$ & $\begin{array}{l}\operatorname{ave}=0.0013 \\
\max =0.0024\end{array}$ & $\begin{array}{l}\operatorname{ave}=0.0028 \\
\max =0.0038\end{array}$ & $\begin{array}{l}\text { ave }=0.0032 \\
\max =0.005\end{array}$ & $\begin{array}{l}\operatorname{ave}=0.0019 \\
\max =0.0026\end{array}$ & $\begin{array}{l}\text { ave }=0.001 \\
\max =0.0017\end{array}$ \\
\hline & $10 \Omega$ & $\begin{array}{l}\text { ave }=0.0009 \\
\mathbf{m a x}=0.0012\end{array}$ & $\begin{array}{l}\text { ave }=0.0024 \\
\max =0.003\end{array}$ & $\begin{array}{l}\text { ave }=0.0065 \\
\max =0.0097\end{array}$ & $\begin{array}{l}\text { ave }=0.0038 \\
\max =0.0072\end{array}$ & $\begin{array}{l}\text { ave }=0.0031 \\
\max =0.0039\end{array}$ \\
\hline & $50 \Omega$ & $\begin{array}{l}\text { ave }=0.048 \\
\mathbf{m a x}=0.058\end{array}$ & $\begin{array}{l}\text { ave }=0.029 \\
\max =0.055\end{array}$ & $\begin{array}{l}\text { ave }=0.13 \\
\max =0.18\end{array}$ & $\begin{array}{l}\operatorname{ave}=0.17 \\
\max =0.18\end{array}$ & $\begin{array}{l}\text { ave }=0.084 \\
\max =0.12\end{array}$ \\
\hline & $100 \Omega$ & $\begin{array}{l}\operatorname{ave}=0.037 \\
\mathbf{m a x}=0.044\end{array}$ & $\begin{array}{l}\text { ave }=0.0007 \\
\mathbf{m a x}=0.0009\end{array}$ & $\begin{array}{l}\text { ave }=0.024 \\
\max =0.029\end{array}$ & $\begin{array}{l}\text { ave }=0.022 \\
\max =0.027\end{array}$ & $\begin{array}{l}\text { ave }=0.0028 \\
\max =0.0033\end{array}$ \\
\hline \multirow{5}{*}{$\begin{array}{c}\text { Two } \\
\text { Phases } \\
\text { To } \\
\text { Ground }\end{array}$} & $0.1 \Omega$ & $\begin{array}{l}\text { ave }=0.0033 \\
\max =0.0078\end{array}$ & $\begin{array}{l}\text { ave }=0.0049 \\
\max =0.0098\end{array}$ & $\begin{array}{l}\text { ave }=0.011 \\
\max =0.025\end{array}$ & $\begin{array}{l}\text { ave }=0.019 \\
\max =0.045\end{array}$ & \\
\hline & $1 \Omega$ & $\begin{array}{l}\text { ave }=0.0037 \\
\mathbf{m a x}=0.0069\end{array}$ & $\begin{array}{l}\text { ave } 0.0046 \\
\max =0.0094\end{array}$ & $\begin{array}{l}\text { ave }=0.015 \\
\max =0.023\end{array}$ & $\begin{array}{l}\text { ave }=0.019 \\
\max =0.042\end{array}$ & $\begin{array}{l}\operatorname{ave}=0.0015 \\
\max =0.0025\end{array}$ \\
\hline & $10 \Omega$ & $\begin{array}{l}\text { ave }=0.0029 \\
\text { max }=0.0051\end{array}$ & $\begin{array}{l}\text { ave }=0.0032 \\
\max =0.0059\end{array}$ & $\begin{array}{l}\text { ave }=0.014 \\
\max =0.019\end{array}$ & $\begin{array}{l}\operatorname{ave}=0.014 \\
\max =0.02\end{array}$ & \\
\hline & $50 \Omega$ & $\begin{array}{l}\text { ave }=0.0036 \\
\max =0.0054\end{array}$ & $\begin{array}{l}\text { ave }=0.004 \\
\max =0.0054\end{array}$ & $\begin{array}{l}\text { ave }=0.032 \\
\max =0.039\end{array}$ & $\begin{array}{l}\operatorname{ave}=0.01 \mathrm{I} \\
\max =0.016\end{array}$ & \\
\hline & $100 \Omega$ & $\begin{array}{l}\text { ave }=0.0025 \\
\max =0.0041\end{array}$ & $\begin{array}{l}\text { ave }=0.014 \\
\max =0.027\end{array}$ & $\begin{array}{l}\text { ave }=0.019 \\
\max =0.038\end{array}$ & $\begin{array}{l}\text { ave }=0.011 \\
\max =0.013\end{array}$ & $\begin{array}{l}\text { ave }=0.019 \\
\max =0.023\end{array}$ \\
\hline \multirow{5}{*}{$\begin{array}{l}\text { Line } \\
\text { To } \\
\text { Line }\end{array}$} & $0.1 \Omega$ & $\begin{array}{l}\text { ave }=0.0029 \\
\max =0.0049\end{array}$ & $\begin{array}{l}\text { ave }=0.0029 \\
\max =0.0056\end{array}$ & $\begin{array}{l}\text { ave }=0.049 \\
\max =0.0083\end{array}$ & $\begin{array}{l}\text { ave }=0.0041 \\
\max =0.0064\end{array}$ & \\
\hline & $1 \Omega$ & $\begin{array}{l}\text { ave }=0.0017 \\
\max =0.0024\end{array}$ & $\begin{array}{l}\text { ave }=0.022 \\
\max =0.029\end{array}$ & $\begin{array}{l}\operatorname{ave}=0.013 \\
\max =0.025\end{array}$ & $\begin{array}{l}\text { ave }=0.0016 \\
\max =0.0042\end{array}$ & $\begin{array}{l}\text { ave }=0.0029 \\
\max =0.0041\end{array}$ \\
\hline & $10 \Omega$ & $\begin{array}{l}\text { ave }=0.0024 \\
\mathbf{m a x}=0.0038\end{array}$ & $\begin{array}{l}\text { ave }=0.0067 \\
\max =0.0097\end{array}$ & $\begin{array}{l}\text { ave }=0.022 \\
\max =0.049\end{array}$ & $\begin{array}{l}\text { ave }=0.0041 \\
\max =0.0062\end{array}$ & $\begin{array}{l}\text { ave }=0.0035 \\
\max =0.0069\end{array}$ \\
\hline & $50 \Omega$ & $\begin{array}{l}\operatorname{ave}=0.034 \\
\max =0.051\end{array}$ & $\begin{array}{l}\text { ave }=0.023 \\
\max =0.031\end{array}$ & $\begin{array}{l}\text { ave }-0.029 \\
\max =0.034\end{array}$ & $\begin{array}{l}\text { ave }=0.044 \\
\max =0.067\end{array}$ & $\begin{array}{l}\text { ave }=0.055 \\
\max =0.067\end{array}$ \\
\hline & $100 \Omega$ & $\begin{array}{l}\text { ave }=0.0059 \\
\max =0.0091\end{array}$ & $\begin{array}{l}\operatorname{ave}=0.18 \\
\max =0.24\end{array}$ & $\begin{array}{l}\text { ave }=0.12 \\
\max =0.22\end{array}$ & $\begin{array}{l}\text { ave }=0.16 \\
\max =0.2\end{array}$ & $\begin{array}{l}\text { ave }=0.13 \\
\max =0.27\end{array}$ \\
\hline \multirow{5}{*}{$\begin{array}{l}\text { Single } \\
\text { Line } \\
\text { To } \\
\text { Ground }\end{array}$} & & $\begin{array}{l}\operatorname{ave}=0.0095 \\
\max =0.019\end{array}$ & $\begin{array}{l}\text { ave }=0.026 \\
\max =0.07\end{array}$ & $\begin{array}{l}\text { ave }=0.034 \\
\max =0.055\end{array}$ & $\begin{array}{l}\text { ave }=0.034 \\
\max =0.054\end{array}$ & $\begin{array}{l}\text { ave }=0.012 \\
\max =0.017\end{array}$ \\
\hline & $1 \Omega$ & $\begin{array}{l}\text { ave }=0,0092 \\
\max =0.017\end{array}$ & $\begin{array}{l}\text { ave }=0.027 \\
\max =0.062\end{array}$ & $\begin{array}{l}\text { ave }=0.049 \\
\max =0.061\end{array}$ & $\begin{array}{l}\text { ave }=0.037 \\
\max =0.056\end{array}$ & $\begin{array}{l}\text { ave }=0.014 \\
\max =0.019\end{array}$ \\
\hline & & $\begin{array}{l}\text { ave }=0.087 \\
\max =0.12\end{array}$ & $\begin{array}{l}\text { ave }=0.032 \\
\max =0.039\end{array}$ & $\begin{array}{l}\text { ave }=0.077 \\
\max =0.098\end{array}$ & $\begin{array}{l}\operatorname{ave}=0.079 \\
\max =0.083\end{array}$ & $\begin{array}{l}\text { ave }=0.032 \\
\max =0.048\end{array}$ \\
\hline & $50 \Omega$ & $\begin{array}{l}\text { ave }=0.0063 \\
\max =0.068\end{array}$ & ave $=0.056$ & $\begin{array}{l}\text { ave }=0.044 \\
\mathbf{m a x}=0.098\end{array}$ & $\begin{array}{l}\text { ave }=0.032 \\
\max =0.037\end{array}$ & $\begin{array}{l}\text { ave }=0.015 \\
\max =0.024\end{array}$ \\
\hline & $100 \Omega$ & $\begin{array}{l}\text { ave }=0.054 \\
\max =0.093\end{array}$ & $\begin{array}{l}\text { ave }=0.067 \\
\max =0.075\end{array}$ & $\begin{array}{l}\text { ave }=0.069 \\
\max =0.095\end{array}$ & $\begin{array}{l}\text { ave }=0.0094 \\
\max =0.014\end{array}$ & $\begin{array}{l}\text { ave }=0.0095 \\
\max =0.02\end{array}$ \\
\hline
\end{tabular}

of the fault location errors are calculated as the average value of five inception angles $\left(0^{\circ}, 45^{\circ}, 90^{\circ}, 135^{\circ}\right.$, and $180^{\circ}$ in relation to the zero cross of $a$-phase voltage). In this table, variable ave is the average fault location with respect to five inception angles. For comparison, variable max is the maximum fault location error in five inception angles. Generally, the maximum error is $0.27 \%$ and the average error is about $0.034 \%$. The error increases in large fault resistance cases. Additionally, if only the normal fault resistance is considered (smaller and equal $10 \mathrm{Ohm}$ [7]), the maximum error can be reduced to $0.12 \%$ and the average error is only $0.0182 \%$.

\section{DISCUSSION}

1) This study has evaluated the performance of the proposed fault location algorithm for transmission line with a se- ries compensation device. Calculated results when only using the prelocation step are sufficiently accurate for most tested cases, especially for the short distance transmission line. However, if the voltage drop of the series device is neglected, the shunt charging current between series device and fault location becomes inconsistent with the adopted line model and harms the accuracy of the fault location. Thus, when the fault resistance is small (reducing the shunt capacitance voltage and shunt current) or when the line length between fault location and series device is short (reducing the total shunt charging capacitor), the prelocation step is sufficient to estimate fault location accurately. However, the prelocation step will provide a worse result given certain special fault events, such as the case 2 mentioned above. To include all possible operation situations, the proposed two-step algorithm must be 
used to estimate fault location. According to our results, the proposed algorithm can provide extremely accurate results for all fault events.

2) Conventional fault location techniques must consider variations of the phasors throughout the fault period to precisely estimate the switching time of various operation modes of series devices when the detailed protection functions of series device are considered. Such an approach will significantly increase the computational burden. In fact, accurately modeling the protection functions of series device and precisely estimating the phasors during faults are extremely difficult. The inaccurate model of device protection function and phasor measurement error in traditional techniques will further worsen the fault location error. Since this algorithm does not use the device model, the precise fault location can be calculated simply from the last measured phasor data from both sides of the transmission lines. Therefore, the computation burden is less than using the conventional technique. Besides, the proposed two-step fault location algorithm is easier to implement than the conventional ones because the operating modes of the series device need not be considered.

3) When a fault occurs and the fault current $\mathbf{I}_{F}$ is large enough, the MOV of the series device will begin to conduct to bypass some fault current. Thus, the equivalent resistance $\mathbf{R}_{S E}$ of (29) must be a positive value [1]. Otherwise, when high impedance ground faults occur, the bypass current of MOV may become very small. Thus, the equivalent resistance $\mathbf{R}_{S E}$ of (29) will shrink and the computed $\mathbf{R}_{S E}$ will oscillate around zero, possibly becoming a small and negative value. Fortunately, the computed $\mathbf{R}_{S E}$ on the incorrect side still remains a relatively large negative value. Thus, the proposed selector can still work properly.

4) Since the series device model is not used in the development of the proposed fault location algorithm, the algorithm's design is independent of the installation of series compensation device. Thus, when the type of series compensation device is changed or the protection function of the series compensation device is tuned, no additional need arises to modify the fault locator. Additionally, the fault locator designer does not require knowledge of series compensation devices to design the locator. Thus, the design of the proposed fault locator is easier than for the conventional locator.

\section{CONCLUSION}

This paper has successfully proposed a novel fault location algorithm for series compensated lines. The proposed algorithm does not utilize the series device model and knowledge of the operation mode of series device to compute the voltage drop during fault.. Thus, the fault location errors induced from incorrect series compensation device model or inaccurate modeling of the series device protection function model can be eliminated completely. Furthermore, because the fault locator designer does not need the series compensation device model to design the fault locator, designing the proposed fault locator becomes easier than in conventional designing. Additionally, the proposed fault location algorithm can be easily applied to any other series compensated line that has no additional shunt branch or phase shift contribution on line current. To select the correct fault location with respect to the series device, this work has presented one skillful selector. To double-check the input fault type, this work has also successfully proposed a method to double-check the input fault type when computing the fault location. The simulation results show the proposed fault location algorithm is useful and easily produces accurate fault location result.

\section{APPENDIX}

\section{A. System Data}

System Voltage: $345 \mathrm{KV}$ System Frequency: $60 \mathrm{~Hz}$

Voltage Source $\mathbf{E}_{\mathbf{S}} \& \mathbf{E}_{\mathbf{R}}$

$E_{S}=1.00^{\circ}$ pu $E_{R}=1.0-10^{\circ}$ pu

Zero-sequence: $2.33+j 26.6 \Omega$

Positive-sequence: $1.31+j 15.0 \Omega$

Transmission Line:

Zero-sequence:

$$
R_{0}=0.275 \Omega / \mathrm{km}, L_{0}=2.7233 \mathrm{mH} / \mathrm{km} \text {, }
$$$$
C_{0}=0.021 \mu \mathrm{H} / \mathrm{km}
$$

Positive-sequence:

$R_{1}=0.0275 \Omega / \mathrm{km}, L_{1}=0.8356 \mathrm{mH} / \mathrm{km}$ ， $C_{1}=0.021 \mu \mathrm{H} / \mathrm{km}$

MOV:

Reference current: $1 \mathrm{kA}$

Reference voltage: $140 \mathrm{kV}$

Exponent: 23

Ratted energy: 5MJ.

\section{B. Demonstration of the Validity of Selector}

In the above one-line-diagram of Fig. 13, assume that the fault is occurred at the right-hand side of the series device. The per-unit fault location $\mathbf{D}$ is the correct fault location and the per-unit fault location $\mathrm{D}^{\prime}$ is assumed as the incorrect fault location. One can get the following relations:

$$
\begin{aligned}
\mathbf{V}_{R} & =\mathbf{D} L \mathbf{Z}_{L} \mathbf{I}_{R}+\left(\mathbf{I}_{S}+\mathbf{I}_{R}\right) \mathbf{R}_{F} \\
& =\mathbf{D}^{\prime} L \mathbf{Z}_{L} \mathbf{I}_{R}+\left(\mathbf{I}_{S}+\mathbf{I}_{R}\right) \mathbf{R}_{F}^{\prime}+\mathbf{I}_{R} \mathbf{Z}_{S E}^{\prime} \\
\mathbf{V}_{S} & =(1-\mathbf{D}) L \mathbf{Z}_{L} \mathbf{I}_{S}+\left(\mathbf{I}_{S}+\mathbf{I}_{R}\right) \mathbf{R}_{F}+\mathbf{I}_{S} \mathbf{Z}_{S E} \\
& =\left(1-\mathbf{D}^{\prime}\right) L \mathbf{Z}_{L} \mathbf{I}_{S}+\left(\mathbf{I}_{S}+\mathbf{I}_{R}\right) \mathbf{R}_{F}^{\prime}
\end{aligned}
$$

equation (B.1) can be reduced as

$$
\mathbf{I}_{R}\left(\mathbf{D}^{\prime}-\mathbf{D}\right) L \mathbf{Z}_{L}+\left(\mathbf{I}_{S}+\mathbf{I}_{R}\right)\left(\mathbf{R}_{F}^{\prime}-\mathbf{R}_{F}\right)+\mathbf{I}_{R} \mathbf{Z}_{S E}^{\prime}=0
$$

Equation (B.2) can be reduced as

$$
\mathbf{I}_{S}\left(\mathbf{D}^{\prime}-\mathbf{D}\right) L \mathbf{Z}_{L}+\left(\mathbf{I}_{S}+\mathbf{I}_{R}\right)\left(\mathbf{R}_{F}-\mathbf{R}_{F}^{\prime}\right)+\mathbf{I}_{S} \mathbf{Z}_{S E}=0 \text {. (B.4) }
$$

In order to simplify (B.4), assuming $\mathbf{I}_{R}=a \mathbf{I}_{S}+$ $j b \mathbf{I}_{S}, \mathbf{Z}_{S E}=\mathbf{R}_{S E}+j \mathbf{X}_{S E}, \mathbf{Z}_{L}=r+j x_{L}, \Delta \mathbf{D}=\left(\mathbf{D}^{\prime}-\mathbf{D}\right)$ and $\Delta \mathbf{R}_{F}=\left(\mathbf{R}_{F}-\mathbf{R}_{F}^{\prime}\right)$ and substituting the above relation 


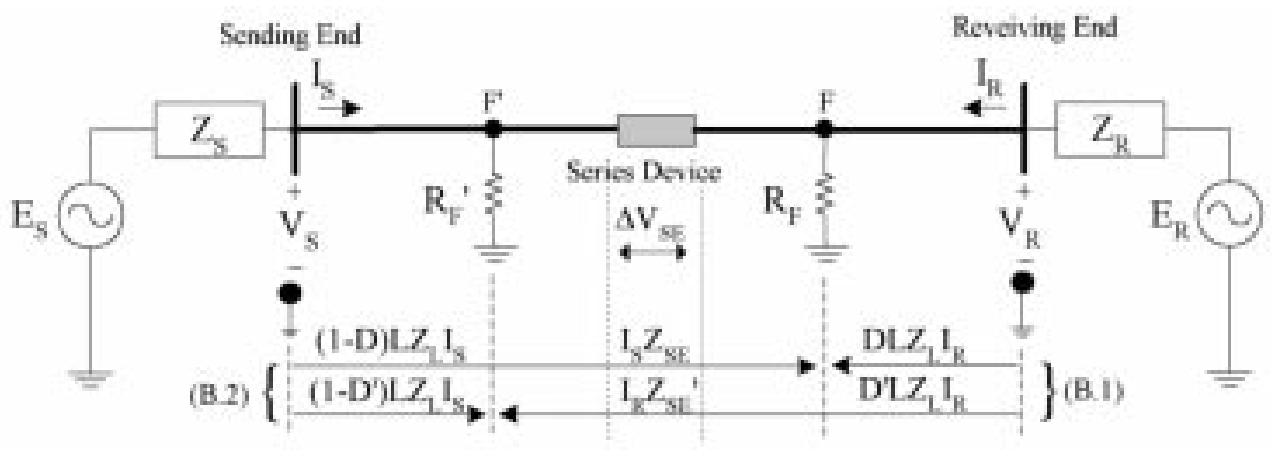

Fig. 13. One-line-diagram for demonstration of selecting algorithm.

into (B.4). Equation (B.4) can be changed to the following form:

$$
\begin{aligned}
\mathbf{I}_{S} \Delta \mathrm{D} L\left(r+j x_{L}\right)+[(1+a) & \left.\mathbf{I}_{S}+j b \mathbf{I}_{S}\right] \Delta R_{F} \\
& +\mathbf{I}_{S}\left(\mathbf{R}_{S E}+j \mathbf{X}_{S E}\right)=0
\end{aligned}
$$

where the parameter $a$ is positive because the angle difference between $I_{R}$ and $I_{S}$ is less than $90^{\circ}$ in this system. In considering the real and imaginary parts of (B.5), one can get the following two relations:

$$
\begin{aligned}
\mathbf{I}_{S}\left[\Delta \mathbf{D} L r+(1+a) \Delta \mathbf{R}_{F}+\mathbf{R}_{S E}\right] & =0 \\
\mathbf{I}_{S}\left(\Delta \mathrm{D} L x_{L}+b \Delta \mathbf{R}_{F}+\mathbf{X}_{S E}\right) & =\mathbf{0} .
\end{aligned}
$$

Since $\Delta \mathrm{D}, a$ and $R_{S E}$ in (B.6) are all positive variables and $\mathbf{I}_{S}$ does not equal zero, one can easily get the following relation:

$$
\Delta \mathbf{R}_{\mathbf{F}}<0 \text {, and } \mathbf{R}_{\mathbf{F}}^{\prime}>\mathbf{R}_{\mathbf{F}} \text {. }
$$

In considering (B.3), assume $\mathbf{I}_{S}=c \mathbf{I}_{R}+j d \mathbf{I}_{R}$ and the parameter $c$ is also greater than zero in this system. Substituting the above relation into (B.3) and assuming $\mathbf{Z}_{S E}^{\prime}=R_{S E}^{\prime}+j X_{S E}^{\prime}$, one can get the following relation:

$$
\begin{aligned}
\mathbf{I}_{R} \Delta \mathrm{D} L\left(r+j x_{L}\right) \bullet[(1+c) & \left.\mathbf{I}_{R}+j d \mathbf{I}_{R}\right] \Delta \mathbf{R}_{F} \\
& +\mathbf{I}_{R}\left(\mathbf{R}_{S E}^{\prime}+j \mathbf{X}_{S E}^{\prime}\right)=0 .
\end{aligned}
$$

Considering the real and image part of (B.9), one can also get the following two equations:

$$
\begin{aligned}
\mathbf{I}_{R}\left[\Delta \mathrm{D} L r \bullet(1+c) \Delta \mathbf{R}_{F}+\mathbf{R}_{S E}^{\prime}\right] & =0 \\
\mathbf{I}_{R}\left(\Delta \mathrm{D} L x_{L}+d \Delta \mathbf{R}_{F}+\mathbf{X}_{S E}^{\prime}\right) & =\mathbf{0} .
\end{aligned}
$$

As the variable $\Delta R_{F}$ in (B.8) has been proven as positive variable and parameter $c$ also positive, one can easily get the following relation from (B.10):

$$
\mathbf{R}_{\mathbf{S E}}^{\prime}<\mathbf{0}
$$

From the above relations of (B.8) and (B.12), choosing between two fault locations of $\mathbf{D}$ and $\mathrm{D}^{\prime}$ is easily made. Two selecting algorithms are written as follows.

i) Choosing the fault location with larger $R_{F}$ as the correct fault location.

ii) Choosing the fault location with positive $R_{S E}$ as the correct fault location.

When the fault occurs at the left-hand side of series device, same results can be given by the same discussions used above.
Both of the algorithms i) and ii) can be used as selecting algorithms. The algorithm i) has only one index $\left(R_{F}\right)$, and is the same as presented in [7]. The algorithm ii) has three indices (three phase $R_{S E}$ ), and carries more information. For example, when $Z_{S E}$ of three-phase system have been calculated, these indices can be used for fault type double-checking.

\section{REFERENCES}

[1] D. L. Goldswortyh, "A linearized model for MOV-protected series capacitors," IEEE Trans. Power Syst., vol. 2, pp. 953-958, Nov. 1987.

[2] N. Christl, R. Hedln, R. Johnson, P. Krausn, and A. Montoya, "Power system studies and modeling for the kayenta 230KV substation advanced series compensation," in IEE Int. Conf., 1991, pp. 33-37.

[3] J. Urbanek, R. J. Piwko, B. L. Damsky, B. C. Furumasu, and W. Mittlestadt, "Thyristor controlled series compensation prototype installation at the slatt 500KV substation," IEEE Trans. Power Delivery, vol. 8, pp. 1460-1469, July 1993.

[4] Y. Tanaka, H. Taniguchi, M. Egawa, H. Fujita, M. Watanabe, and H. Konishi, "Using a miniature model and EMTP simulations to evaluate new methods to control and protect a thyristor-controlled series compensator," in IEEE Winter Meeting, 1999.

[5] F. Ghassemi, J. Goodarzi, and A. T. Johns, "Method to improve digital distance relay impedance measurement when used in series compensated lines protected by a metal exide Varistor," IEE Proc. Gener. Transm. Distrib., vol. 145, pp. 403-408, July 1998.

[6] D. Novosel, B. Bachmann, Y. Hu, and M. M. Saha, "Algorithm for location faults on series compensated lines using neural network and deterministic methods," IEEE Trans. Power Delivery, vol. 11, pp. 1728-1736, Oct. 1996.

[7] M. M. Saha, J. Izykowski, E. Rosolowski, and B. Kasztenny, "A new accurate fault locating algorithm for series compensated lines," IEEE Trans. Power Delivery, vol. 14, pp. 789-797, July 1999.

[8] A. A. Girgis, A. A. Sallam, and E.-D. A. Karim, "An adaptive protection scheme for advanced series compensated (ASC) transmission lines," IEEE Trans. Power Delivery, vol. 13, pp. 414-420, Apr. 1998.

[9] A. K. S. Chaudhary, K. S. Tam, and A. G. Phadke, "Protection system representation in the electromagnetic transient program," IEEE Trans. Power Delivery, vol. 9, pp. 700-711, Apr. 1994.

[10] B. Lian and M. M. A. Salama, "An overview of digital fault location algorithm for power transmission lines using transient waveforms," Elect. Power Syst. Res., vol. 29, pp. 17-25, 1994.

[11] J. A. S. B. Jayasinghe, R. K. Aggarwal, A. T. Johns, and Z. Q. Bo, “A novel nonunit protection for series compensated EHV transmission lines based on fault generated high frequency voltage signals," IEEE Trans. Power Delivery, vol. 13, pp. 405-413, Apr. 1998.

[12] M. Kezunovic, J. Mrlic, and B. Perunicic, "An accurate fault location algorithm using synchronized sampling," Elect. Power Syst. Res., vol. 2, pp. 161-169, 1994.

[13] J. A. Jiang, J. Z. Yang, Y. H. Lin, C. W. Liu, and J. C. Ma, "An adaptive PMU based fault detection/location technique for transmission lines-Part I: Theory and algorithms," IEEE Trans. Power Delivery, vol. 5, pp. 1136-1146, Oct. 2000

[14] J. A. Jiang, Y. H. Lin, J. Z. Yang, T. M. Too, and C. W. Liu, "An adaptive PMU based fault detection/location technique for transmission lines-Part II: PMU implementation and performance evaluation," IEEE Trans. Power Delivery, vol. 5, pp. 486-493, Apr. 2000. 
[15] J. Z. Yang and C. W. Liu, "A precise calculation of power system frequency and phasor," IEEE Trans. Power Delivery, vol. 5, pp. 494-499, Apr. 2000.

[16] — "Complete elimination of DC offset in current signals for relaying applications," in IEEE Winter Meeting, 2000.

[17] C. A. Gross, Power System Analysis. New York: Wiley, 1986.

[18] J. R. Rice, Numerical Methods, Software, and Analysis. San Diego, CA: Academic, 1993

[19] H. Dommel, Electromagnetic Transient Program. Portland, OR: BPA, 1986.

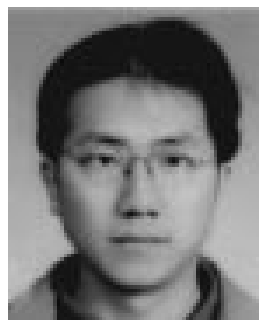

Chi-Shan Yu was born in Taipei, Taiwan in 1966. He received the B.S. and M.S. degrees in electrical engineering from National Tsing Hua University in 1988 and 1990, respectively.

$\mathrm{He}$ is a candidate for the Ph.D. degree in the Electrical Engineer Department at National Taiwan University, Taipei, Taiwan. His current research interests are computer relaying and transient stability controller.

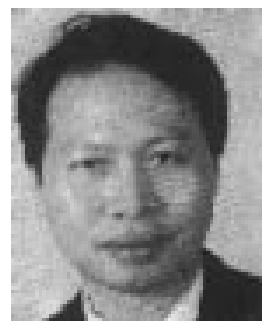

Chih-Wen Liu (S'93-M'96) was born in Taiwan in 1964. He received the B.S. degree in electrical engineering from National Taiwan University in 1987, and the M.S. and Ph.D. degrees in electrical engineering from Cornell University in 1992 and 1994.

Since 1994, he has been with National Taiwan University, where he is Associate Professor of electrical engineering. His main research area is in application of computer technology to power system monitoring, operation, protection, and control.

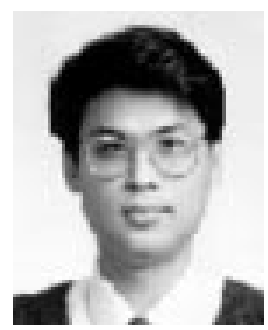

Sun-Li Yu was born in Taipei in 1965. He graduated in electrical engineering from the National Taipei Institute of Technology in 1985. He passed the national examination of electrical engineering in 1987 . He received the M.S.E.E. degree from the National Tsing Hua University, Hsinchu, Taiwan, in 1990.

$\mathrm{He}$ has been an instructor at the Kuang-Wu Institute of Technology since 1992. He joined the $\mathrm{Ph} . \mathrm{D}$. program in Electrical Engineering in NTUST in September 1996.

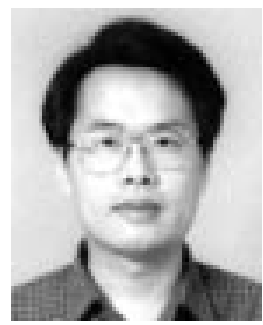

Joe-Air Jiang was born in Taipei in 1963. He graduated from National Taipei University of Technology in 1983 and received M.S. and Ph.D. degrees in electrical engineering from National Taiwan University, Taipei, Taiwan in 1990 and 1999.

Since 1990, he has been with Private Kuang-Wu Institute of Technology and Commerce, where he is Assistant Professor of electrical engineering. His area of interest is in computer relaying and bio-effects of EM-wave. 